\title{
32. VERTICAL SEISMIC PROFILE AT SITE 765 AND SEISMIC REFLECTORS IN THE ARGO ABYSSAL PLAIN ${ }^{1}$
}

\author{
S. T. Bolmer, ${ }^{2}$ R. T. Buffler, ${ }^{3}$ H. Hoskins, ${ }^{2}$ R. A. Stephen, ${ }^{2}$ and S. A. Swift ${ }^{2}$
}

\begin{abstract}
The first Ocean Drilling Program (ODP) vertical seismic profile (VSP) experiment in a thick sedimentary section was conducted at Site 765 to measure compressional wave velocities and to correlate drilling results with seismic data. Measurements were performed through the cased portion of the hole between 186 and $915 \mathrm{mbsf}$ using both air-gun and water-gun sources. Average velocities for the air-gun source were $1.967 \mathrm{~km} / \mathrm{s}(284-915 \mathrm{mbsf}), 1.815 \mathrm{~km} / \mathrm{s}(186-284$ $\mathrm{mbsf}$ ), and $1.633 \mathrm{~km} / \mathrm{s}$ (seafloor to $186 \mathrm{mbsf}$, extrapolated). Separation of the wavefield into upgoing and downgoing components by $\mathrm{f}-\mathrm{k}$ filtering plus deconvolution of the upgoing wavefield produced good VSP records and revealed reflectors that correlate well with seismic profiles. These data were used to correlate the drilling results (lithologic units) with the seismic sequences at the drill site, which will be used to extrapolate the drilling results regionally. A weak sub-basement reflection at approximately $600 \mathrm{~m}$ into basement may correspond to the contact between pillow basalts and sheet flows. A comparison between VSP velocities, laboratory measurements, and sonic logs shows generally good agreement below about 420 mbsf.
\end{abstract}

\section{INTRODUCTION}

In a zero-offset vertical seismic profile (Gal'perin, 1974; Hardage, 1983; Balch and Lee, 1984), a seismometer is clamped in a borehole at different depths, and the seismic wavefield generated from a source at the surface directly above the borehole is recorded. This technique bridges the observational gap between surface reflection profiling at frequencies of $10-200 \mathrm{~Hz}$ and borehole sonic logs at frequencies of $10-20 \mathrm{kHz}$. It measures directly the in-situ wavefield generated by standard seismic sources as it propagates through the earth around the borehole. This technique is used extensively in the petroleum exploration industry and is beginning to be used regularly during ODP operations.

Some scientific applications and advantages of conducting a zero-offset VSP experiment, such as that conducted during Leg 123 , are described briefly as follows:

1. Depth vs. arrival time data from the downgoing wavefield provide a direct tie between the drilled section and the surface seismic records. Accurate depths to specific seismic sequences and their boundaries can be determined. An accurate correlation between borehole structure and seismic data maximizes drilling results and facilitates the extrapolation of results regionally, beyond the site area. Velocity/depth profiles found using wide-angle seismic reflection/refraction methods are often limited by assumptions about the local velocity-depth structure (flat, laterally homogeneous layers with constant, isotropic velocity, bounded by sharp interfaces) that are rarely met. Sonic log velocities usually are inadequate because the sonic frequency is much greater than that used in seismic reflection. Coverage of the borehole is usually incomplete (e.g., compressional-wave velocity of sediments is not acquired through casing) and measurement errors often occur.

\footnotetext{
${ }^{1}$ Gradstein, F. M., Ludden, J. N., et al., 1992. Proc. ODP. Sci. Results, 123: College Station, TX (Ocean Drilling Program).

2 Department of Geology and Geophysics, Woods Hole Oceanographic Institution, Woods Hole, MA 02543 , U.S.A.

${ }^{3}$ Institute for Geophysics, University of Texas at Austin, 8701 Mopac Blvd., Austin, TX 78759, U.S.A.
}

2. Analysis of downgoing and upgoing wavefields reveal the change of seismic wavetrains with depth and the physical changes in rock properties that are responsible for the character of observed reflections. A VSP experiment records both the direct, downgoing waves, as well as the upgoing waves that are reflected from interfaces (impedance changes) below the clamping depth. Processing techniques can be used to separate the downgoing from the upgoing wavefields.

3. Downgoing wavefields can be used to define accurately deconvolution operators for removing source signatures from the upgoing, reflected wavefield.

4. The seismogram produced by a VSP is a better representation of the reflection profile than a synthetic seismogram generated from the sonic log. It more nearly approximates the arrival times and wave shapes of the surface-recorded reflection record.

5. Interval velocities of the section drilled (sediments and oceanic crust) can be determined by calculating the difference in arrival times of the direct, downgoing wave between receiver depths. This velocity information can be correlated with borehole lithology and is important for understanding the physical properties of the rocks drilled. These data, acquired in situ at seismic frequencies $(10-200 \mathrm{~Hz})$, supplement the data from sonic logs and laboratory measurements of cores.

6 . The VSP technique can be used to image interfaces and structure beneath the borehole and to predict the depth to reflectors ahead of the drill bit.

7. By using a three-component geophone, both $P$ - and $S$-wave data can be obtained for a more detailed analysis of rock properties and lithology. Even for compressional waves at normal incidence, scattering, particularly in the crust, can introduce energy onto the horizontal components. The ratio of energy on vertical vs. horizontal components can be a measure of scattering strength (Dougherty and Stephen, 1988).

Since 1961, borehole seismic experiments have been conducted as part of ocean drilling with varying degrees of success. A brief history and summary of these experiments is included in a workshop report on vertical seismic profiling (Mutter and Balch, 1987). Prior to Leg 123, four VSP's had been conducted at ODP, including an offset experiment during Leg 102 (Shipboard Scientific Party, 1986; Swift et al., 1988) and conventional zero-offset 
VSP's during Leg 104 (Shipboard Scientific Party, 1987; Rutledge and Winkler, 1989), Leg 111 (Shipboard Scientific Party, 1988), and Leg 118 (Shipboard Scientific Party, 1989; Swift et al., 1990). Increased use of conventional zero-offset VSP's at ODP is the result of several factors, including (1) a more routine use of VSP's in industry, (2) the drilling of deeper holes with good accompanying seismic data for regional extrapolation, and (3) a greater appreciation in the scientific community for the value of downhole logging. All of these previous experiments addressed problems related specifically to oceanic crust.

Site 765 provided the first opportunity for ODP to conduct a conventional zero-offset VSP in a thick sedimentary section specifically meant for stratigraphic analysis. The excellent multifold seismic data collected by the Australian Bureau of Mineral Resources (MR) allowed us to develop a detailed seismic stratigraphic framework for the thick sedimentary section in the Argo Abyssal Plain (see "Seismic Stratigraphy" section, Shipboard Scientific Party, 1990). One of the primary scientific objectives of the VSP experiment was the correlation of borehole results with the defined seismic sequences. This should allow for a more complete extrapolation of drilling results throughout the Argo Abyssal Plain using existing seismic data and for a more complete interpretation of the depositional and structural history of the adjacent Exmouth Plateau margin.

Understanding the nature and origin of oceanic crust in the southeastern Argo Abyssal Plain is another important problem addressed at Site 765. The site is located near a complex continent/ocean boundary in one of the oldest areas of Indian Ocean crust. Thus, another major objective of the VSP experiment was to obtain detailed velocity and structural information from the upper part of the oceanic crust for comparison with drilling results. The experiment also would allow us to image subcrustal reflections and structure below the borehole.

This chapter addresses the following three major objectives of the Site 765 experiment: (1) to determine the compressional-wave velocity as a function of depth; (2) to correlate reflection events between multifold and singlefold seismic-reflection profiles and the VSP experiment and to relate these to physical property measurements of core samples; and (3) to identify and determine the depth of sub-basement reflectors.

\section{FIELD METHODS}

\section{Sources}

During Leg 123, we used equipment and procedures that were employed in oblique seismic experiments and vertical seismic profiles from earlier drilling legs (Stephen, 1979; Swift et al., 1990). Specific procedures for this VSP experiment were described by the Shipboard Scientific Party of Leg 123 (1990, p. 235-244) and are not repeated here.

The source configuration was the same as that used for the VSP experiment during Leg 118 (Swift et al., 1990), following the methods used during Legs 104 and 111 (see fig. 141 in Shipboard Scientific Party, 1990). Two seismic sources were deployed: a 1000 -in. ${ }^{3}$ air gun and a 400 -in. ${ }^{3}$ water gun. The water gun provided high-frequency energy for better resolution of the shallower sedimentary section, while the air gun provided low-frequency energy for deeper penetration (Figs. 1 and 2). Gun depths were chosen to give the best source signature, using the waveforms observed with a monitoring hydrophone suspended at 250 mbsl (Swift et al., 1990). Shot instants were detected by a blast phone near the guns and were used to begin digitization of the seismic data streams.

Figure 1 shows typical pressure/time curves for the air-gun and water-gun sources, as observed on the deep monitoring hydro-

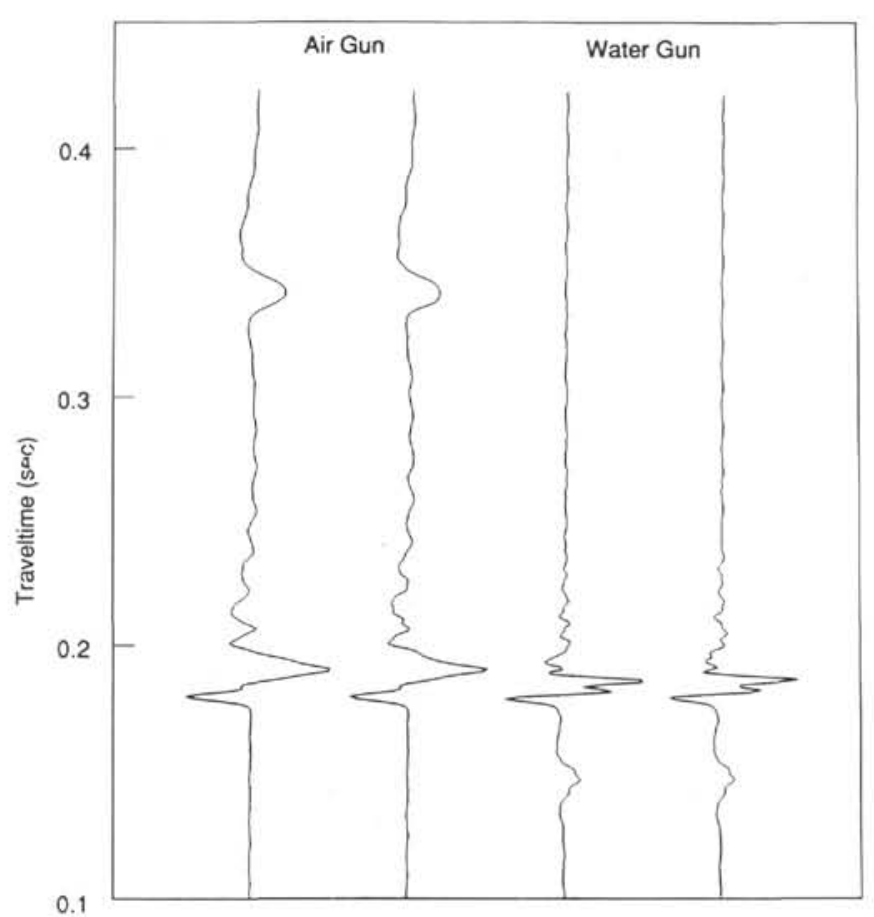

Figure 1. Typical air- and water-gun source signatures are shown as observed from a monitoring hydrophone suspended about $250 \mathrm{~m}$ below the guns. The water gun is more impelling but does have a low-amplitude, low-frequency precursor. The bubble pulse for the air gun has a period of about $140 \mathrm{~ms}$. The water gun essentially has no bubble pulse.

phone. The air gun has a sharp rise time, followed by a negative excursion that is a combination of the phase-inverted reflection from the sea surface and the collapse of the bubble. The bubble expands again at about $140-150 \mathrm{~ms}$ intervals (the bubble pulse period). The water-gun signal is different. The initial, small positive, and negative excursions at $140 \mathrm{~ms}$ correspond to water being driven out of the chamber. The shorter, higher-amplitude oscillations at 170-200 ms correspond to the collapse of the air cavity. The water gun does not generate a significant resonant bubble (Parkes and Hatten, 1986).

The air gun has significant energy up to $150 \mathrm{~Hz}$, and the water gun has significant energy up to $250 \mathrm{~Hz}$ (Fig. 2). (The spectra in Figure 2 include the bubble pulses.) There are two factors that modulate the spectra of the downgoing wavefront. One is the effect of the phase-inverted and delayed surface reflection. This is the modulation at multiples of about $100 \mathrm{~Hz}$ for the air gun and $150 \mathrm{~Hz}$ for the water gun. The second is the bubble pulse interval. The air gun is the $7-\mathrm{Hz}$ "comb" feature. The water gun has a smoother spectra than the air gun and is a better source for detecting the "impulse response" of the drilled section at 15-95 $\mathrm{Hz}$. These frequencies correspond to wavelengths of 130 to $20 \mathrm{~m}$, respectively, in material with a velocity of $2 \mathrm{~km} / \mathrm{s}$. Figure 2 also shows spectra of the two sources as observed on a geophone at 341 mbsf (solid line). They show much of the same spectral structure as the near sea surface measurements (dashed line).

The autocorrelation of the air-gun source (Fig. 3) shows coherences at shifts of 150 and $300 \mathrm{~ms}$ corresponding to the bubble pulse interval. The water-gun autocorrelation shows some small coherences at about 20 and $40 \mathrm{~ms}$, probably corresponding to the expulsion of water from the gun. The two sources show negative coherences at about 10 and $7 \mathrm{~ms}$, respectively, corresponding to the surface-reflection delays. The width of the principal energy in the autocorrelation function is a measure of the minimum separation of observably distinct reflectors. 

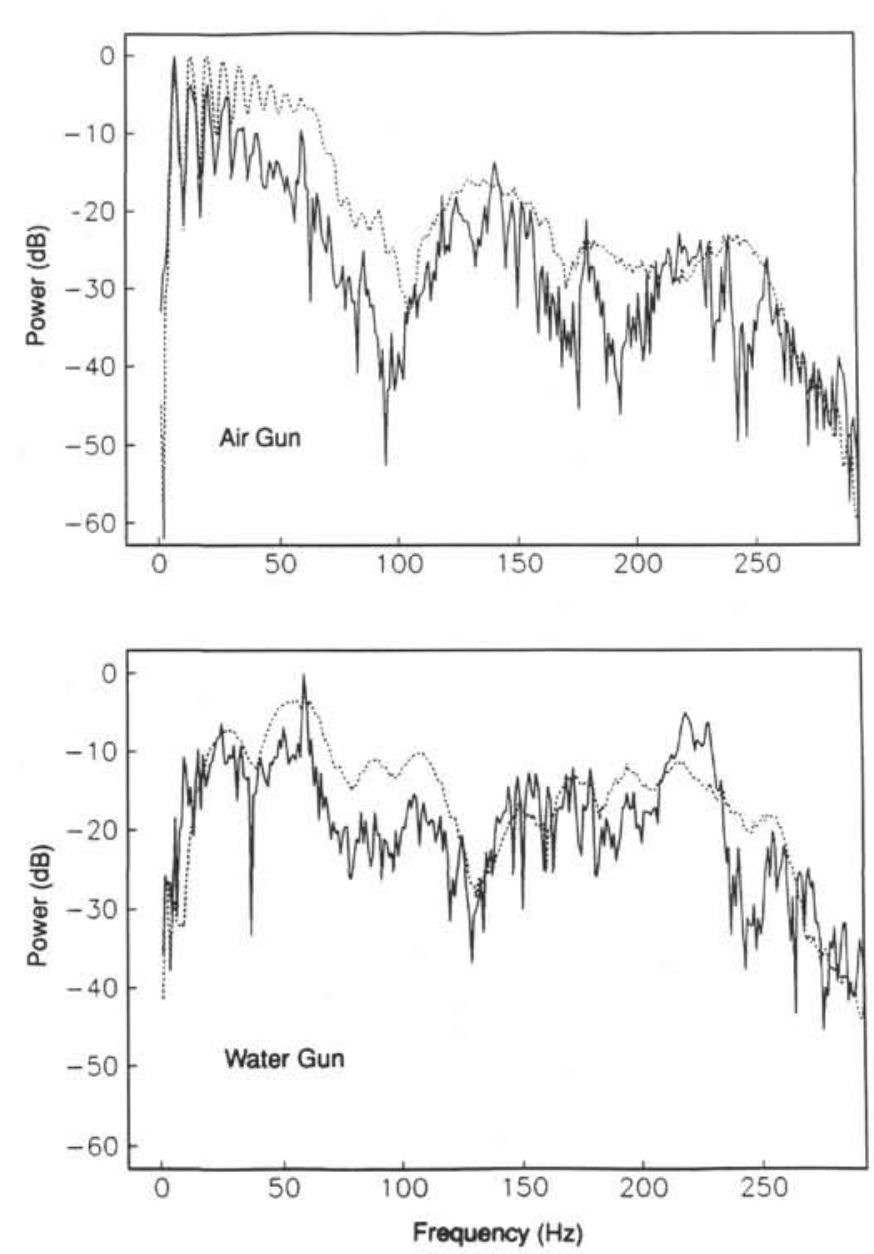

Figure 2. Spectra of the air- and water-gun signals, as observed from the monitoring hydrophone (dashed line), indicate that the water gun has a flatter response and higher frequency content than the air gun. Spectra for the two sources observed from the vertical component geophone at $341 \mathrm{mbsf}$ (solid line) show that energy is lost in distinct bands and is not a simple function of frequency, as predicted by an attenuation model. The seafloor reflection-transmission process and/or interference of multiples in the sediment also have an effect. The hydrophone spectra were computed at $1.0-\mathrm{s}$ intervals, whereas the borehole receiver spectra were computed at 0.55 -s intervals.

The air- and water-gun source signatures are clearly visible in both the direct and basement-reflected signals (Fig. 4). This, together with the peaked autocorrelation of the two sources, suggests that deconvolution treatment of the reflections would be useful in determining the impulse response (see "Processing" section, this chapter).

\section{Receiver}

Two Geospace wall-lock seismometers were available for the VSP experiment; each contained three pairs of $4.5-\mathrm{Hz}$ geophones. Each pair is wired in series and orthogonally configured with two components in the plane normal to the borehole and one parallel to the borehole. The orientation of the horizontal phones was not monitored. The near critically damped geophones have a flat response from 4.5 to $100 \mathrm{~Hz}$. We restricted our analysis to the vertical component data because signal levels on the horizontal channels were only slightly higher than background noise and the horizontal channels did not show any new arrivals, such as converted shear waves.

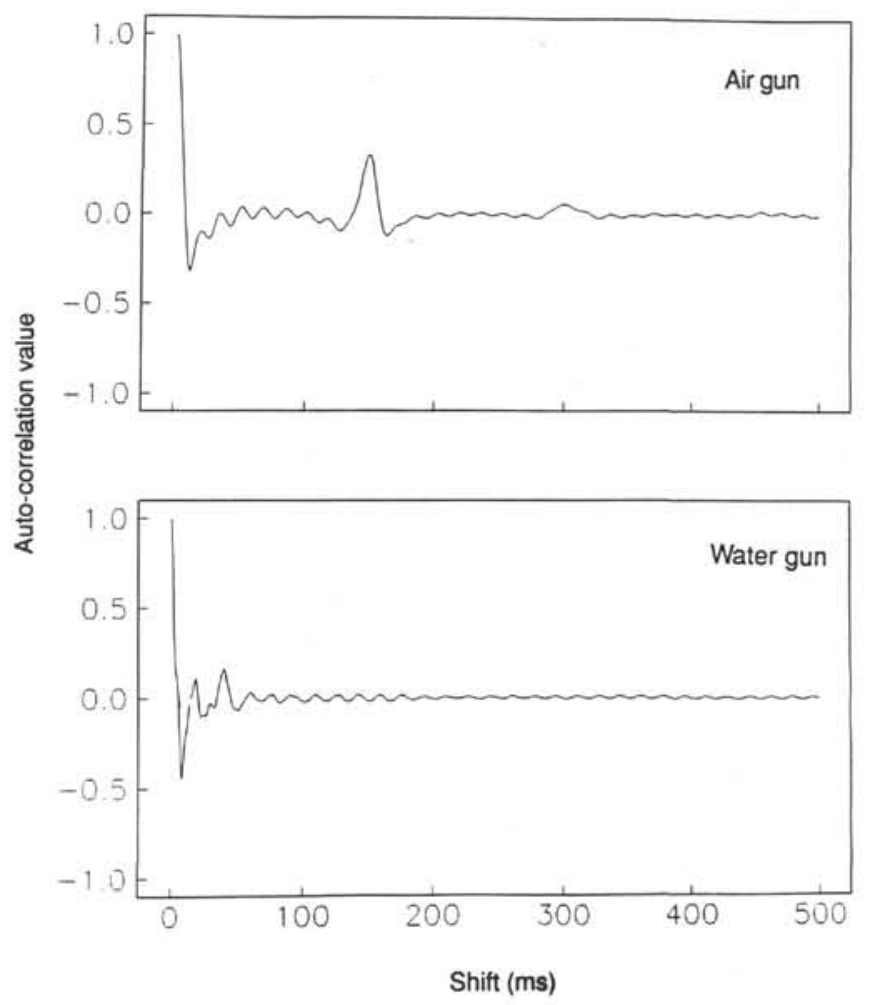

Figure 3. The autocorrelation of the air- and water-gun source signatures reveals that the bubble-pulse period of the air gun is about 140 to $150 \mathrm{~ms}$. The water gun does not have a discernable bubble pulse. Autocorrelation is a measure of how well distinct reflectors can be resolved.

The tool was positioned in the hole by initially lowering it to the bottom and extending its clamping arm. (The maximum extension of the spring-loaded arm is approximately $40 \mathrm{~cm}$ from the side of the tool.) The logging cable was then slacked about $2 \mathrm{~m}$ to mechanically decouple the heave of the ship from the tool. The amount of slack in the logging cable has to be carefully chosen. If too little slack is in the cable, the ship's heave will tug on the seismometer, producing noise. If too much slack is in the cable, loops of logging cable may wrap around the tool, possibly fouling the clamping arm and damaging the lower end of the cable (our experience during Leg 102).

Once fully extended in a hole of uniform diameter, such as casing, the arm can be left extended and the tool dragged from station to station. This saves time between stations and removes the possibility of failure of the clamping motor.

The meter wheel readings on the logging cable are remarkably precise. The hysteresis on a $6000 \mathrm{~m}$ lowering is typically only a few meters. The incremental movement of the tool, however, is not as well determined because the tool may slip within the borehole by an amount up to the difference between the amount of slack and the heave of the ship. We were fortunate in this experiment in that the heave was only about $1-2 \mathrm{~m}$ and that the ship held its heading between $201^{\circ}$ and $211^{\circ}$ for the 24 -hr duration. We assign an uncertainty of up to $1 \mathrm{~m}$ in tool position at each station. Clamping at $20-\mathrm{m}$ intervals gives rise to a potential interval velocity error of $\pm 0.20 \mathrm{~km} / \mathrm{s}$.

The shipboard party tried several times to clamp the tool in the open basement hole at locations where the caliper log indicated that the hole was less than $40 \mathrm{~cm}$ in diameter (i.e., within reach of the tool's clamping arm). The caliper log (Shipboard Scientific Party, 1990, p. 258-259) shows that the 257-m portion of the hole in basement has wide variations in size. The hole was drilled with 
Air Gun Traveltime (sec)

4.5

5.0

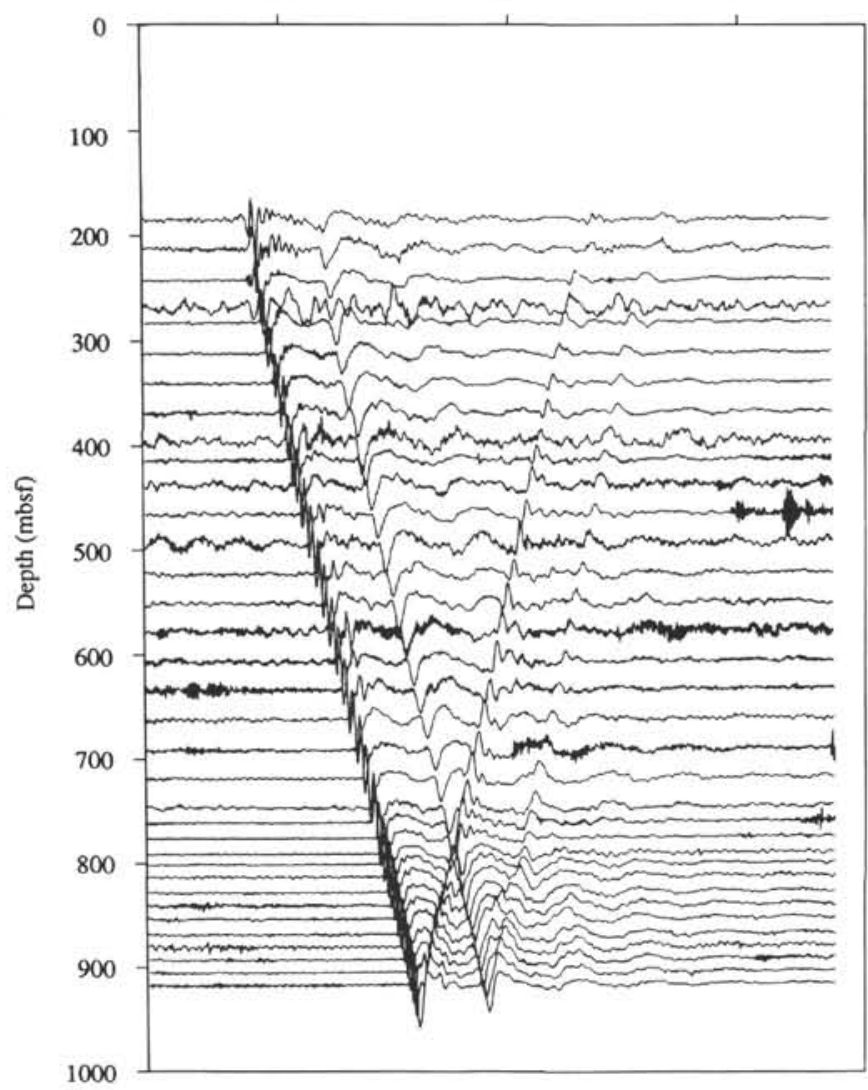

Figure 4. The unprocessed, but summed, traces are shown after timing corrections have been applied for both the air and water guns. Signal-tonoise ratios vary considerably (traveltimes are for one-way propagation).

a 14-3/4-in. bit to $948 \mathrm{~m}$ ( $15 \mathrm{~m}$ below the casing and $20 \mathrm{~m}$ into basement). The bottom $242 \mathrm{~m}$ of the hole was drilled with a $9-7 / 8$-in. bit. Apparently, the basement was so poorly consolidated that the borehole wall was unstable and sections of the wall fell into the hole. The seismometer signals showed that the clamping arm had not held the tool and that it had slid down and stopped on the logging cable. Our three attempts to clamp in the lower, uncased basement portion of the hole were unsuccessful. Our first secure clamping was achieved in the bottom of the casing at 915 mbsf, $13 \mathrm{~m}$ above basement, in the sedimentary section. There is no indication that the presence of the casing has distorted the seismic signals.

\section{Recording}

The signals from the three seismic channels and the monitoring hydrophone were recorded on board the ship both digitally (Weiderspahn, 1985) and on an analog tape. The signals were digitized at $1000 \mathrm{~Hz}$ for a 9-s duration for each of the three seismic channels and a 1-s duration for the hydrophone and recorded on 9-track tape in SEG-Y format. Air- and water-gun sources were fired alternately at each depth. In all, 1085 shots (528 air-gun and 557 water-gun shots) were recorded at 41 depths. Of these, 336 (202 air-gun and 134 water-gun shots) at 31 depths were used (Table 1). A number of shots were fired from each gun at each depth, and the traces for individual shots were summed to improve the signal-to-noise ratio. Shots that were not used either had an

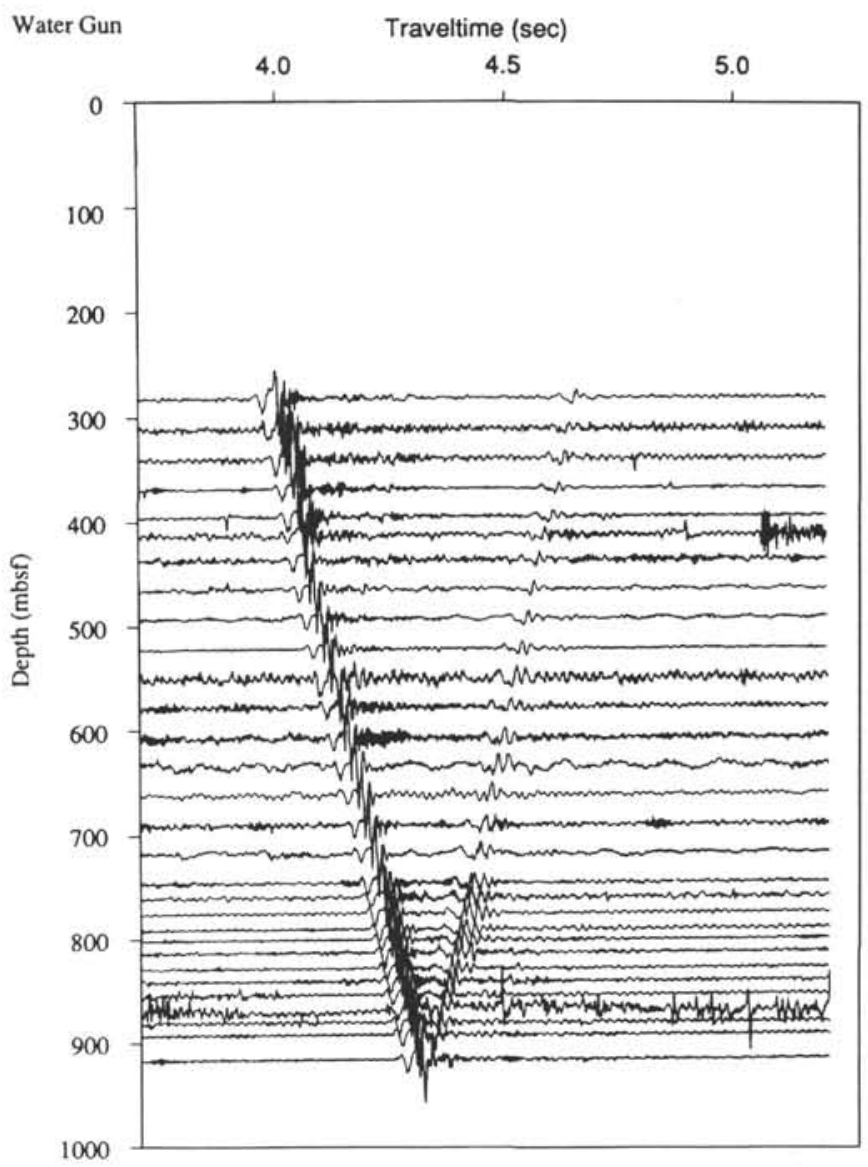

Figure 4 (continued).

unacceptable signal-to-noise ratio or had unresolvable timing problems.

The shot instant was determined with a blast phone mounted midway between the two guns. The output of the blast phone was level-discriminated in an ancillary part of the Underway Geophysics Laboratory "black box," and the time measured was entered automatically into the SEG-Y header record. We do not understand the details of this system, which is part of the shipboard equipment, but considerable variation in the time between the trigger pulse to the guns and the start of sequence on the computer was noted, greatly frustrating our summing of shot records. The delay in air-gun firing from the start of sequence pulse varied up to $72 \mathrm{~ms}$. The delay in the water-gun firing varied up to $62 \mathrm{~ms}$. These delays would remain stable for several shots and then jump to a different value. In normal air-gun operations, the variation in this delay is $1 \mathrm{~ms}$ or less. The performance of the automatic picking system (the shot-instant discriminator) should be checked. For this data set, we have done the best we can to correct for this scatter in timing.

Our primary purpose for suspending the hydrophone at a $250-\mathrm{m}$ depth below the drilling ship was to monitor the stability of the downgoing "far field" waveform; however, this was also useful for corroborating the variations in shot instants from the blast phone. The geophone arrival times on the raw traces were much more consistent when referenced to the hydrophone arrival times than to the logged shot instants. Consequently, correct shot instants were obtained using the variations in hydrophone arrival times, and the quality of the summed traces was improved. The summed traces, with the timing corrections applied, are shown in 
Table 1. Shot statistics for Site 765 VSP.

\begin{tabular}{|c|c|c|c|c|c|c|c|}
\hline \multirow[b]{2}{*}{$\begin{array}{l}\text { Station } \\
\text { depth } \\
\text { (mbsf) }\end{array}$} & \multicolumn{3}{|c|}{ Air gun } & \multicolumn{3}{|c|}{ Water gun } & \multirow[b]{2}{*}{$\begin{array}{c}\text { Time } \\
\text { difference } \\
\text { (ms) }\end{array}$} \\
\hline & $\begin{array}{l}\text { Shots } \\
\text { used }\end{array}$ & $\begin{array}{c}\text { Shots } \\
\text { acquired }\end{array}$ & $\begin{array}{c}\text { Arrival } \\
\text { time } \\
\text { (s) }\end{array}$ & $\begin{array}{l}\text { Shots } \\
\text { used }\end{array}$ & $\begin{array}{c}\text { Shots } \\
\text { acquired }\end{array}$ & $\begin{array}{c}\text { Arrival } \\
\text { time } \\
\text { (s) }\end{array}$ & \\
\hline 99 & & 5 & & & 3 & & \\
\hline 129 & & 10 & & & 14 & & \\
\hline 143 & & & & & 25 & & \\
\hline 186 & 3 & 8 & 3.894 & & 12 & & \\
\hline 214 & 3 & 13 & 3.912 & & 15 & & \\
\hline 244 & 8 & 10 & 3.924 & & 11 & & \\
\hline 270 & 9 & 50 & 3.940 & & 31 & & \\
\hline 284 & 7 & 14 & 3.948 & 7 & 22 & 3.975 & 27 \\
\hline 313 & 8 & 25 & 3.964 & 2 & 29 & 3.989 & 25 \\
\hline 341 & 10 & 39 & 3.980 & 4 & 45 & 4.000 & 20 \\
\hline 369 & 6 & 15 & 3.994 & 5 & 14 & 4.012 & 18 \\
\hline 396 & 4 & 17 & 4.006 & 4 & 23 & 4.025 & 19 \\
\hline 414 & 7 & 16 & 4.015 & 2 & 14 & 4.033 & 17 \\
\hline 438 & 4 & 14 & 4.026 & 5 & 12 & 4.044 & 18 \\
\hline 466 & 6 & 10 & 4.040 & 6 & 15 & 4.056 & 16 \\
\hline 494 & 4 & 14 & 4.052 & 9 & 18 & 4.069 & 17 \\
\hline 523 & 5 & 10 & 4.070 & 7 & 10 & 4.084 & 14 \\
\hline 551 & 3 & 4 & 4.083 & 2 & 5 & 4.096 & 13 \\
\hline 578 & 7 & 12 & 4.098 & 5 & 16 & 4.113 & 15 \\
\hline 607 & 6 & 15 & 4.111 & 4 & 23 & 4.130 & 19 \\
\hline 634 & 4 & 12 & 4.126 & 5 & 20 & 4.144 & 18 \\
\hline 662 & 6 & 8 & 4.140 & 4 & 7 & 4.158 & 18 \\
\hline 691 & 5 & 12 & 4.154 & 5 & 12 & 4.172 & 18 \\
\hline 718 & 5 & 6 & 4.168 & 4 & 9 & 4.185 & 17 \\
\hline 746 & 5 & 11 & 4.182 & 6 & 9 & 4.198 & 16 \\
\hline 760 & 5 & 8 & 4.190 & 5 & 12 & 4.206 & 16 \\
\hline 775 & 4 & 11 & 4.197 & 5 & 14 & 4.214 & 17 \\
\hline 790 & 5 & 5 & 4.204 & 5 & 8 & 4.223 & 19 \\
\hline 800 & 7 & 9 & 4.210 & 5 & 10 & 4.229 & 19 \\
\hline 812 & 9 & 34 & 4.217 & 6 & 7 & 4.234 & 17 \\
\hline 827 & 6 & 9 & 4.225 & 4 & 6 & 4.241 & 16 \\
\hline 839 & 7 & 11 & 4.232 & 3 & 5 & 4.248 & 16 \\
\hline 852 & 7 & 13 & 4.239 & 4 & 8 & 4.255 & 16 \\
\hline 867 & 6 & 14 & 4.246 & 1 & 1 & 4.262 & 16 \\
\hline 879 & 4 & 12 & 4.252 & 5 & 12 & 4.267 & 15 \\
\hline 891 & 4 & 7 & 4.258 & 3 & 7 & 4.272 & 14 \\
\hline 903 & 8 & 14 & 4.264 & & & & \\
\hline 915 & 5 & 8 & 4.269 & 2 & 4 & 4.282 & 13 \\
\hline 1131 & & & & & 27 & & \\
\hline 1143 & & 6 & & & 11 & & \\
\hline 1158 & & 17 & & & 11 & & \\
\hline Totals & $\overline{202}$ & $\overline{528}$ & & $\overline{134}$ & $\overline{557}$ & Average & $\overline{17.3}$ \\
\hline
\end{tabular}

Figure 4. The two obvious arrivals are the direct energy and the reflected energy from basement.

\section{DATA PROCESSING}

\section{Initial Processing at Sea}

Initial processing was performed on board the JOIDES Resolution using the Computing Center's VAX 11-750. The SEG-Y tapes were reformatted into ROSE format (LaTraille, 1983), and all shots at each depth were plotted. From these plots, the "clean" shots were selected. To average out random background noise, the selected traces were summed. These summed traces were plotted in a time vs. depth below seafloor format for a "first look" at the VSP experiment (Shipboard Scientific Party, 1990, figs. 143 and 144). Arrival times were chosen and a traveltime vs. depth curve plotted for each source type (Shipboard Scientific Party, 1990, fig. 145). These indicated that the velocity for the sediment section was approximately $2 \mathrm{~km} / \mathrm{s}$ and was uniform. A depth plot of interval velocities between each clamping position showed considerable scatter. At-sea processing demonstrated that the data were of useful quality. However, it was apparent that the shot instants varied with respect to the start of recording sequence and that timing corrections of the data were needed (see "Recording" section, this chapter).

\section{Background Noise}

The 9-s-long recording window provided us with an opportunity to examine the background noise during intervals before and after the arrival of the air- and water-gun signals. The signal-tonoise ratio of the shots varied greatly. Some traces are "clean," with signal-to-noise ratios greater than $20 \mathrm{Db}$ and with hardly any noise before the first arrival. Some examples of noise are shown in Figure 5. We interpret these as follows:

1. $60-\mathrm{Hz}$ noise from electrical pickup as intermittent ground loops.

2. Objects falling down the hole, expressed as short, high-amplitude bursts. (These intervals can be muted before summing traces.)

3. The tool stopping on the logging cable, when the ship heaved, a "rumbly" noise that persists for much of the trace.

4. The drill pipe hitting the side of the hole, creating a $12-\mathrm{Hz}$ pipe resonance.

The bottom of the drill pipe was $84 \mathrm{mbsf}$, and the drill pipe was suspended on the ship's heave compensator during the experiment, which reduced its vertical motion. The noise level increased at stations higher in the hole, indicating that movement 


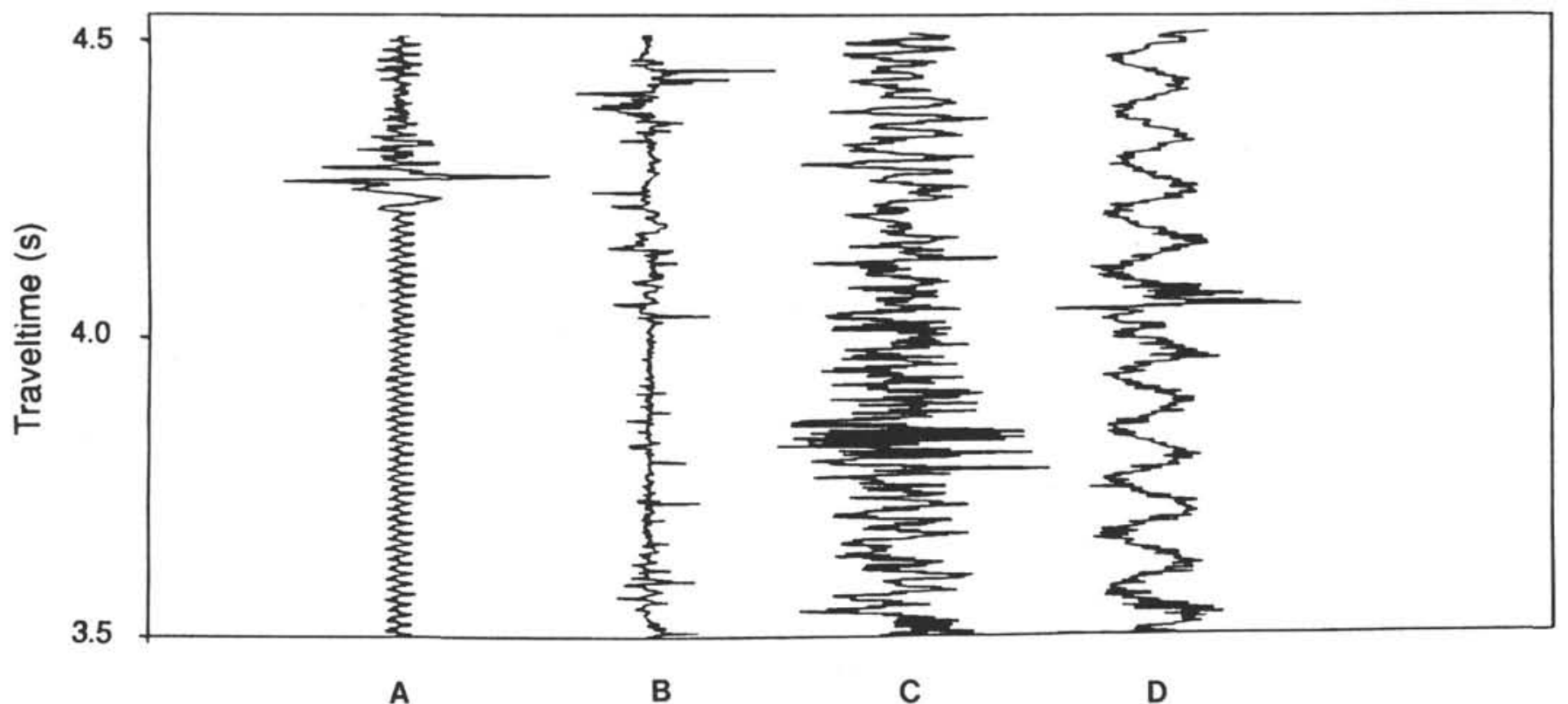

Figure 5. Four commonly observed sources of noise. A. $60-\mathrm{Hz}$ electrical pickup. B. Short bursts from objects falling on the tool. C. Rumbling from heave and tugging from the logging cable. D. A $12-\mathrm{Hz}$ pipe resonance caused by banging of the drill pipe in the hole.

of the drill pipe against the reentry cone and casing remains a major source of the noise. However, no apparent relationship between the seismometer output and the heave of the ship and drill pipe was found by monitoring the seismic noise levels while watching the heave compensator on the ship.

\section{Arrival Time Analysis}

Figure 6 shows the direct arrival times (Table 1) vs. depth for the air and water guns. Superimposed on each plot is the linear least-squares fit to the data. The air-gun traveltimes appear to fall into three linear segments (Fig. 6A). The velocity for the section between 284 and $915 \mathrm{mbsf}$ is $1.967 \mathrm{~km} / \mathrm{s}$. Between 186 and 284 mbsf the velocity is $1.815 \mathrm{~km} / \mathrm{s}$. From $186 \mathrm{mbsf}$ to the seafloor, the extrapolated velocity is $1.633 \mathrm{~km} / \mathrm{s}$. The water-gun traveltime had more scatter, and only a single line could be fit to the data (Fig. 6B). The water-gun velocity is $1.975 \mathrm{~km} / \mathrm{s}$. The $95 \%$ confidence limits for the 284-915 mbsf segment computed using the student's t-statistic are 0.012 and $0.018 \mathrm{~km} / \mathrm{s}$ for the air and water gun, respectively. The linear fit is extremely good, indicating that essentially there is no major velocity gradient between 284 mbsf to basement.

A major function of the VSP is to provide time vs. depth information for converting reflection profiles from time sections to depth sections. To apply the VSP data to the reflection data, one must ensure that the time to some common datum is the same in both data sets. We chose this datum to be the basement contact (Fig. 6A). The basement traveltime was found for each VSP air-gun shot. The difference between the VSP basement traveltime and the reflection traveltime was $17 \mathrm{~ms}$. The VSP traveltimes were shifted $+17 \mathrm{~ms}$ to fit the two-way basement reflection time of $8.562 \mathrm{~s}$.

In the last column of Table 1 , we compare the arrival times between the air-gun and water-gun sources. The air-gun arrival time is earlier than that of the water gun by a mean difference of $17.3 \mathrm{~ms}$. We attribute this time shift to the difference in waveforms between the sources and to the static shifts applied. Allowing for a 17-ms offset between sources, the agreement between the arrival times from the two types of sources is good within $4 \mathrm{~ms}$.
We computed interval velocities by dividing the time differences between adjacent receiver locations by the receiver separation (Fig. 7). These show considerable scatter, with unrealistically low values of almost $1 \mathrm{~km} / \mathrm{s}$ and high values of almost $3 \mathrm{~km} / \mathrm{s}$. An estimate of the velocity resolution can be obtained by considering a $60-\mathrm{Hz}$ wave incident on two receivers $20 \mathrm{~m}$ apart in sediment having a velocity of $2 \mathrm{~km} / \mathrm{s}$. For good quality data, arrival times can be chosen to a tenth of a period or $1.67 \mathrm{~ms}$. This discrepancy in time leads to a discrepancy in velocity (as measured over 20 m) of $0.40 \mathrm{~km} / \mathrm{s}$. Obviously, higher frequency data will be required for better resolution (e.g., $0.10 \mathrm{~km} / \mathrm{s}$ ); however, attenuation in the sediments and other propagation losses limit the high-frequency penetration considerably (Fig. 2). Uncertainty in receiver depths degrades velocity resolution by an additional $0.20 \mathrm{~km} / \mathrm{s}$ (see "Receiver" section, this chapter). Thus, the scatter in the interval velocities (Fig. 7) is not unreasonable, given the timing and depth resolution of this experiment. A three-point average of these interval velocities does give a smoother, more meaningful result (dashed line, Fig. 7A).

\section{Full Waveform Processing}

The VSP data were processed to reduce noise and to separate the upgoing and downgoing wavefields. We followed the general procedures in Lee and Balch (1983) and Hardage (1983) and used the specific methodologies applied by Swift et al. (1990) to the VSP data collected in Hole 735B. Our objectives were as follows:

1. To isolate the reflected wavefield from the downgoing one.

2. To reduce interference from random noise sources.

3. To remove the source signatures and give a band-limited impulse response.

Data obtained using air- and water-gun sources were processed similarly, with only slight differences in processing parameters.

We first summed individual shots at each receiver depth to reduce noise. We qualitatively selected the shots having the highest signal-to-noise ratio. The data were time-shifted to align the shot instants, and the mean values (DC bias) were removed prior to summing. Table 1 shows the total number of shots collected at 
each depth and the number of shots in the summed traces. The summed traces are shown in Figure 4.

A quick-look image of the upgoing wavefield can be obtained simply by shifting the records at each depth by the traveltime of the direct wave to that depth (Hardage, 1983, p. 153-155; Kommedal and Tjøsthein, 1989, p. 118). Events reflected from flat horizons line up horizontally. The time-shifted record sections of unprocessed summed traces (Fig. 8) do not show any obvious reflection events having significant amplitude other than the basement reflection at about $8.5 \mathrm{~s}$.

Wavefield separation was conducted by frequency-wave number (f-k) velocity filtering (Hardage, 1983, p. 174-182; Christie et al., 1983). We subsampled the set of summed traces to approximate constant receiver spacing. In the deeper portion of the hole, where the VSP data are more closely sampled, summed traces from alternate receivers were used to achieve a more even spread. Records were not obtained at a small enough depth interval over the full depth of the hole to avoid spatial aliasing during the $f-k$ separation for all frequencies available from the air- and watergun sources. With a receiver spacing of $28 \mathrm{~m}$ (Fig. 9) and a minimum velocity of $1.6 \mathrm{~km} / \mathrm{s}$, our data are spatially aliased at frequencies greater than $29 \mathrm{~Hz}$ (Hardage, 1983, p. 106-114). The amplitudes at frequencies above $28 \mathrm{~Hz}$ for the air-gun data and 25 $\mathrm{Hz}$ for the water-gun data were attenuated (64 Db/octave) before the $f-k$ transform to avoid contaminating the $f-k$ section with artifacts from the aliased data.

Prior to the Fourier transform, the maximum amplitude in each shot was scaled to a constant value for all shots to eliminate amplitude scaling problems encountered when collecting the data. After transformation into the $\mathrm{f}-\mathrm{k}$ domain, the amplitudes in the downgoing quadrants were zeroed to leave just the upgoing field. Sharp changes in amplitude at the edges of quadrants can cause ringing in the processed records (Christie et al., 1983). Cosine tapers of $\sim 5 \%$ in frequency and $10 \%$ in wave number were used on all quadrant edges to reduce ringing in the inverse FFT section.

The upgoing and downgoing waveforms are shown in Figures 10 and 11 . The four traces plotted between 90 and 150 mbsf are a stack of the other traces, which improves the signal-to-noise ratio and the identification of reflectors. The upgoing wavefield (Fig. 10) for both sources shows additional reflections throughout the sediment column, especially between 8.0 and $8.2 \mathrm{~s}$. These reflections were not discernible in the unfiltered sections (Fig. 8).

The downgoing wavefield (Fig. 11) shows the incident waveform as it was modified by propagation through the sediments. The air-gun waveform is much broader than the water-gun waveform ( $500 \mathrm{~ms}$ vs. $100 \mathrm{~ms}$ ) because of the resonant bubble.

To remove the long source signature in the upgoing wavefields (particularly for the air gun), we deconvolved the upgoing wavefield (Fig. 10) at each receiver depth with the downgoing waveform (Fig. 11) at that depth. We used the spectral division method (Dey-Sarker and Wiggins, 1976; Swift et al., 1990). Low values in the spectra of the downgoing energy were raised to reduce noise generated by the spectral division. By trial and error, we qualitatively found an adequate trade-off between noise reduction and resolution by setting the minimum value at 0.01 times the maximum spectral amplitude. We used $0.45 \mathrm{~s}$ of the air-gun source signature and $0.15 \mathrm{~s}$ of the water-gun signature.

The resolution of reflectors in the deconvolved upgoing wavefields (Fig. 12) is better than that without deconvolution, and both sources exhibit the same reflectors. (Note that the polarity of the reflection sequence in the deconvolved traces is the same for both air and water guns, since the waveform effects have been removed.) After deconvolution, a second mid-sediment reflector can be seen for both sources, and a weak sub-basement reflector also is seen at $8.86 \mathrm{~s}$ in the air-gun data. The air-gun source has a lower frequency content and gets better penetration.
The waveforms in Figures 10 and 11 are not as impelling as in Figures 4 and 8 because of filtering required to avoid spatial aliasing. The air-gun waveform, both the primary and the bubble pulse, consists of three large excursions. However, the water-gun waveform consists of five large excursions. This is a combination of the effect of the low-frequency precursor (Fig. 1) and of the filtering. Also, the polarity of the air- and water-gun waveforms appears reversed. This is imply the low-frequency response of the guns.

\section{DISCUSSION}

\section{Correlation of Laboratory, Sonic Log, and VSP Velocities}

The results of the VSP experiment at Site 765 were used to correlate seismic data available at the site with the drilling results. This correlation will allow for the regional extrapolation of the drilling results using the existing seismic data in the Argo Abyssal Plain, which in turn, will allow for a revised interpretation of the geologic history of the region. Shown here are a few examples of how these VSP results are used in the correlation.

The correlations were performed two separate ways. First, the plot of air-gun first arrivals (in two-way traveltime) vs. depth (Fig. 6A) was used for a direct correlation between preliminary seismic sequences ( 1 through 7 ) defined at the drill site (see "Seismic Stratigraphy" section, Shipboard Scientific Party, 1990) with the lithologic units defined in the hole (Fig. 13). Portions of the two seismic lines at the site showing the seismic sequences are included in Figure 13. The left line is the processed singlefold water-gun line (ODP Line 1) shot during Leg 123 as the site was approached. The right line is a portion of BMR multifold site-survey Line $56 / 22$ that crosses the site, which was shot with an air-gun source. Note the different frequency content between the two sources. The two-way traveltimes for the sequence boundaries were projected down to where they intersect the curve. These points then were projected laterally to intercept the depth in the well.

Figure 13 shows the correlation between the seismic sequences and the lithologic units. The boundary between seismic sequences 1 and 2 occurs near the late Pliocene/Pleistocene boundary and also toward the base of a thick debris flow unit (Subunit IB). The sequence $2 /$ sequence 3 boundary corresponds to the lithologic Unit I/Unit II boundary, marking a reduction in clayey background material. The sequence 3 /sequence 4 boundary occurs within a thick interval of redeposited calcareous sediments (turbidites), where there is no obvious lithologic break. There does occur at this level, however, a slight increase in lithification from oozes to chalks with a corresponding increase in measured velocities. The sequence $4 /$ sequence 5 boundary corresponds to the top of a series of high-amplitude, continuous reflections. This prominent seismic change correlates approximately with a significant influx of background clay in the sediments, lithologic unit IIB. the sequence $5 /$ sequence 6 boundary occurs within lithologic Subunit IIIA, midway between two thick calcareous turbidite units. Although no lithologic break was noted, there is a hiatus (unconformity?) here between the early Oligocene and early Eocene. The sequence $6 /$ sequence 7 boundary at the base of a series of low-frequency, high-amplitude, continuous reflections (sequence 6) occurs at the base of an early Tertiary-Late Cretaceous condensed section. The actual sequence boundary projects into an Albian clay and chalk unit (Subunit IVB). The high-amplitude reflection at the base of sequence 7 corresponds to the top of oceanic crust.

Another method for confirming the correlation between the seismic data and the drilling results is to compare the processed VSP seismograms (Fig. 12) with the sea-surface reflection data. 


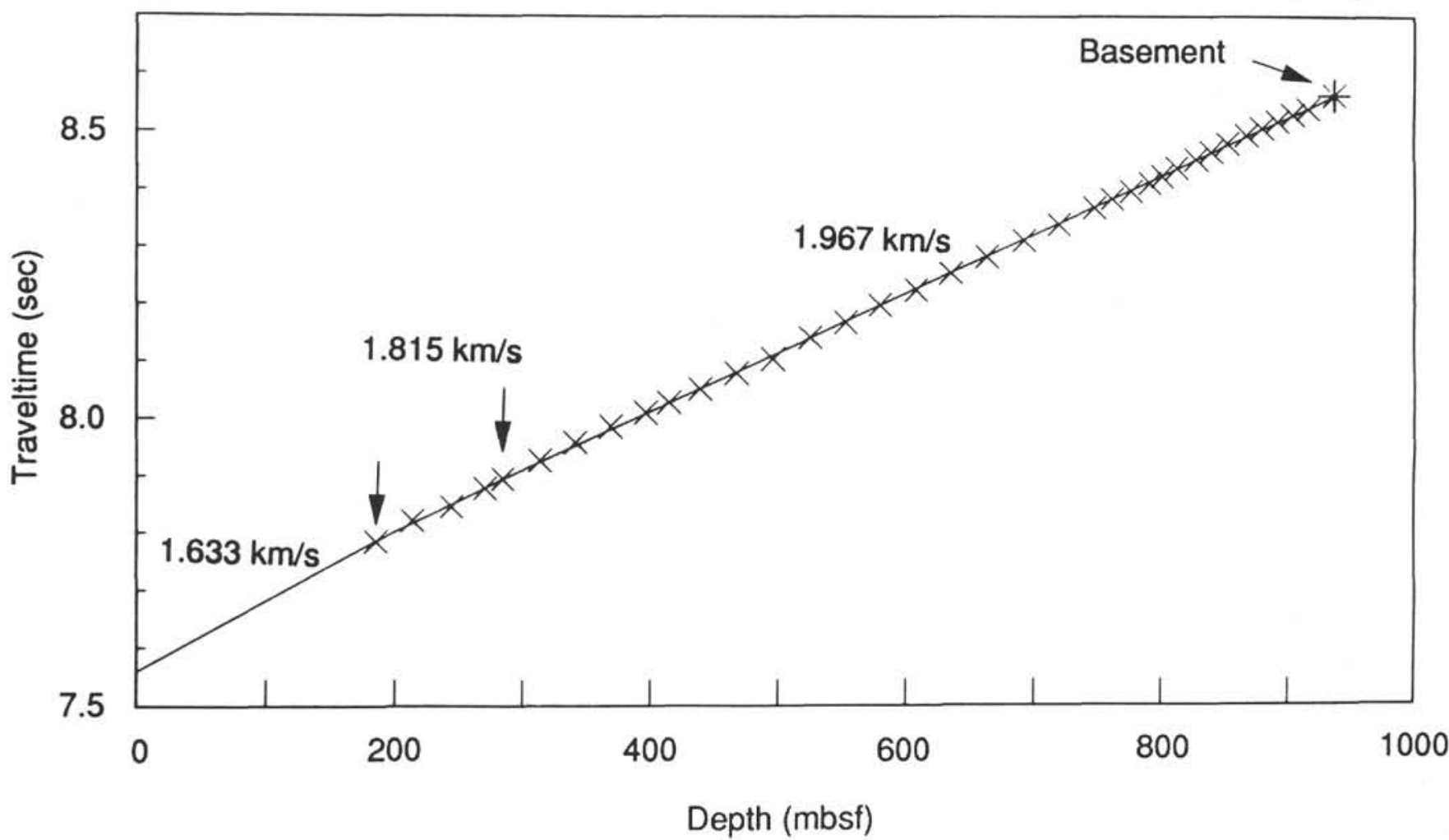

Figure 6. Velocities over thick sections of sediment are obtained by linear least-squares fit to the selected arrival times for both the air (A) and water(B) guns. The air-gun data have been shifted so that the basement arrival time agrees with the two-way basement reflection time from surface profiling $8.562 \mathrm{~s}$. In Figure $6 \mathrm{~A}$, the basement's arrival is shown as a star $\left(^{*}\right)$ and fits the least-square line well. The velocities for the three segments in Figure $6 \mathrm{~A}$ also are shown. In Figure 6A, the arrows at 186 and $284 \mathrm{mbsf}$ show where the different segments start.

In Figure 14, the deconvolved air-gun seismogram from Figure $12 \mathrm{~A}$ is compared with the deconvolved BMR seismic Line $56 / 22$, also shot with an air-gun source. In both, the bubble pulse is virtually eliminated. The stacked VSP traces correlate well with the seismic line. The generally low-amplitude section down to $8.05 \mathrm{~s}$ (top of sequence 5) corresponds to the zone of low-amplitude reflections of sequences 1 through 4 . A small positive reflection at approximately $7.9 \mathrm{~s}$ correlates with the sequence $3 /$ sequence 4 boundary. The higher amplitude reflections between 8.05 and $8.25 \mathrm{~s}$ correlate with the group of high-amplitude, continuous reflections on the seismic lines (sequences 5 and 6). One anomaly is the high amplitude reflections between 8.25 and 8.55 $\mathrm{s}$ on the VSP stacked trace, which do not show up on the seismic line within sequence 7 . There is an excellent correspondence between the high-amplitude basement reflections on both seismograms. This diagram also can be used to correlate the seismic data with the lithologic units in the drill hole (Fig. 14). The results are similar to those in the previous paragraph based on Figure 13.

Figure 15 shows the deconvolved water-gun seismogram from Figure $12 \mathrm{~B}$ shot with a 400 -in. ${ }^{3}$ gun, compared with ODP Line 1, which was shot with two 80 -in. ${ }^{3}$ water guns. This line has been minimally processed (filter, trace-mix, AGC) and has not been deconvolved. Again, there is good correlation, particularly between the higher amplitude reflections between approximately 8.05 and $8.25 \mathrm{~s}$ in the VSP stacked traces and the higher amplitude reflections of sequences 5 and 6 on the seismic line. The reflections seen between $8.25 \mathrm{~s}$ and basement in the air-gun VSP stacked seismogram are not as obvious on the water-gun VSP stacked seismogram. The basement reflections again correlate well. The correlations with the drill-site lithologic units are approximately the same as presented in Figure 13.

\section{Correlation of Laboratory, Sonic Log, and VSP Velocities}

Figure 16 presents the VSP velocities taken from Figures $6 \mathrm{~A}$ and $7 \mathrm{~A}$ superimposed on the laboratory and sonic log velocities. Above $186 \mathrm{mbsf}$, the extrapolated VSP velocity is about $0.1 \mathrm{k} / \mathrm{s}$ faster than the laboratory-measured velocities from cores. No sonic $\log$ data was acquired in this interval. This section corresponds to unlithified redeposited calcareous sediments of pelagic nature with minor clay. Core samples have almost certainly been disturbed by a combination of the drilling process, the coring process, and recovery back to the surface. These disturbances should separate the sedimentary particles in the core, resulting in lower velocities relative to in-situ values.

Between about 186 and $340 \mathrm{mbsf}$, the sediments begin to lithify and the velocities increase. The average VSP velocity is midway between the laboratory velocities and the sonic logs. Again, the lower laboratory velocities probably result from the disturbances mentioned previously. Below about $340 \mathrm{mbsf}$, the redeposited calcareous sediments become more consolidated and lithified, and the measured velocities in the laboratory, although scattered, approach more closely the VSP and sonic velocities. Between 300 and $420 \mathrm{mbsf}$, the sonic log velocities are significantly higher than the VSP velocities. Below that, all of the velocities are still somewhat scattered, but they are in much closer agreement and straddle the $1.967-\mathrm{km} / \mathrm{s}$ VSP least-squares fit line.

Because both VSP and sonic log velocity data are vertical velocity measurements, we cannot resort to anisotropy to explain 


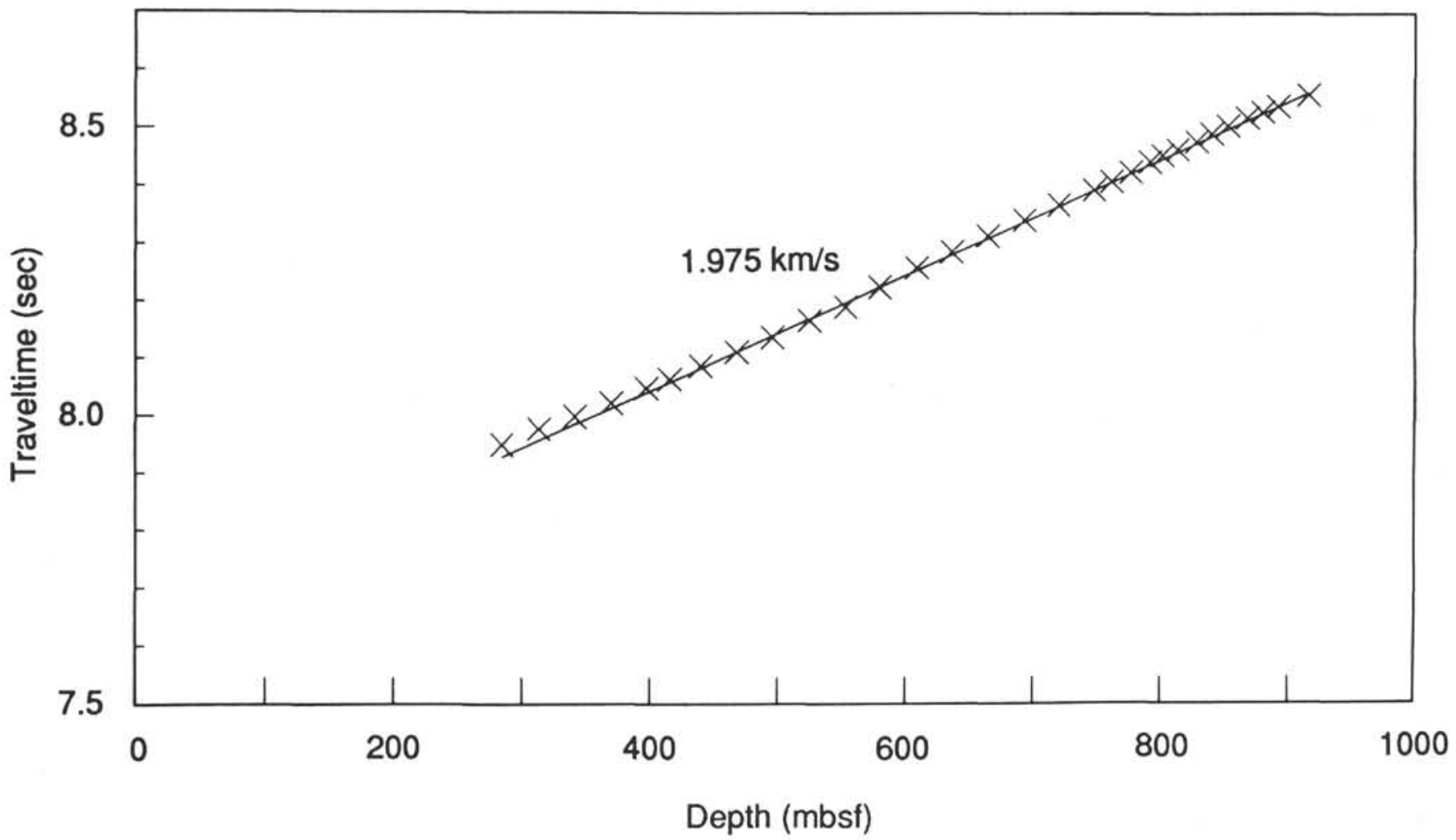

Figure 6 (continued).
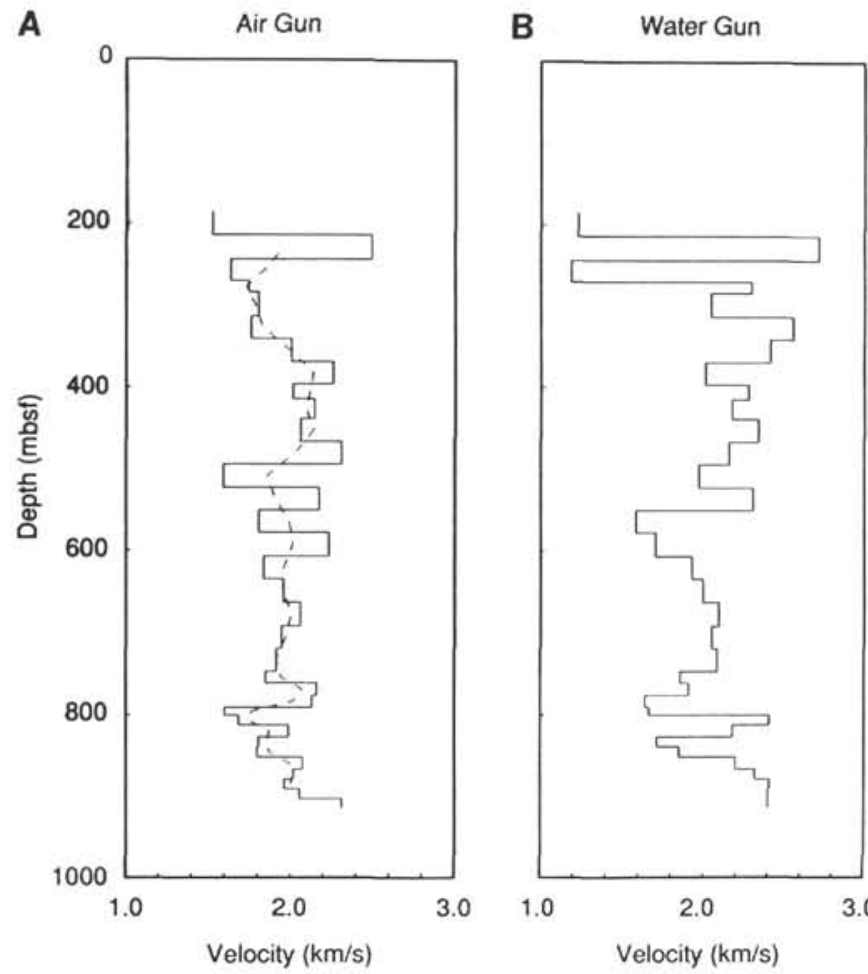

Figure 7. A. Interval velocities, determined from the arrival times at adjacent receivers, show considerable scatter from receiver depth and timing errors. B. Three-point average of the air-gun values gives a smoother, more meaningful function (shown in $\mathbf{A}$ as dashed line. the observed differences, especially between 300 and 420 mbsf. One explanation may be the formation of mud cake along the borehole wall during drilling. In an uncased hole, the drill cuttings and mud returning to the seafloor can become caked onto the borehole wall and for a short way into the formation by a positive pressure gradient between the borehole fluid and the formation. This mud cake will reduce the porosity of the sediments and increase the velocity adjacent to the hole, thus accounting for the higher sonic velocities recorded over this interval. Below this, the more consolidated, lower porosity sediments are less altered by the mud cake, and the velocities are more similar.

\section{Attenuation and Dispersion}

By comparing the spectra of the "far-field" source pulse in the water with the observed field in the hole (Fig. 2), we should be able to estimate attenuation in the sediments. Energy in bands from 40 to 125,180 to 210 , and 240 to $270 \mathrm{~Hz}$ is more attenuated than the energy in the rest of the spectrum. This phenomenon must be associated with the reflection process at the seafloor and within the sedimentary column. A simple attenuation model should give a spectrum having monotonically lower amplitudes at higher frequencies.

Dispersion or frequency-dependent velocity is associated with attenuation and has been observed in sediments. We are tempted to speculate that the velocity differences between the air- and water-gun sources $1.967 \pm 0.012$ and $1.975 \pm 0.018 \mathrm{~km} / \mathrm{s}$, respectively, were caused by dispersion. The difference in velocity of $0.008 \mathrm{~km} / \mathrm{s}$ is not unreasonable between frequencies of $2-50 \mathrm{~Hz}$ for the air gun and $10-230 \mathrm{~Hz}$ for the water gun (Collins, 1988). Further analysis of attenuation and dispersion in this data set is warranted. 


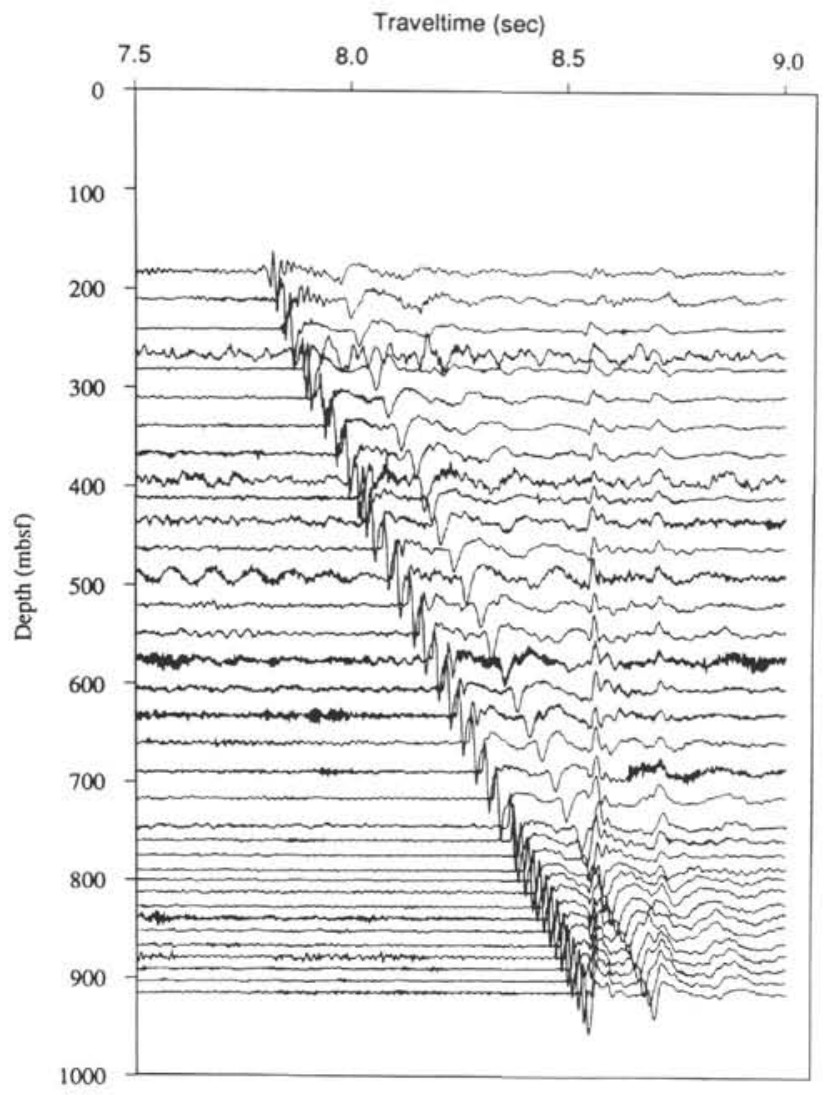

Figure 8. By shifting the traces of the direct-wave arrival time, upgoing energy from reflectors will line up horizontally. These traces are the same as those in Figure 4. Only the direct wave and basement reflections ( 8.5 s) can be identified in the air-and water-gun profiles (traveltimes are for two-way propagation).

\section{The Basement Reflection}

The principal impedance contrast in the hole is the sedimen$\mathrm{t} / \mathrm{b}$ asement interface at $8.562 \mathrm{~s}$. The reflection from the basement is in-phase, and its amplitude ratio to the direct arrival is about $0.45 \mathrm{~s}$, which compares with the $0.55 \mathrm{~s}$ predicted by the lithology change assuming planar surfaces.

\section{The Sub-Basement Reflection}

Assuming a basement velocity of $4.0 \mathrm{~km} / \mathrm{s}$, the sub-basement reflector at $8.86 \mathrm{~s}$ (Fig. 12) ( $0.3 \mathrm{~s}$ after the basement reflector) should be at a depth of $0.6 \mathrm{~km}$ into the crust, possibly corresponding to a reflector in layer 2 , perhaps a contact between pillow basalts and sheet flows. The velocity structure of layer 2 is unknown at the site. The sonobuoy refraction survey conducted by scientists on the JOIDES Resolution (Lizzaralde and Buffler, this volume) had an insufficient range and an insufficient signalto-noise ratio to provide a velocity profile of basement.

The sub-basement reflector is not a pegleg multiple of sediment reflectors. The closest strong and coherent sediment reflector to basement is $0.25 \mathrm{~s}$ above basement, and its pegleg should appear $0.50 \mathrm{~s}$ after the basement reflection. The sub-basement reflector is $0.3 \mathrm{~s}$ after the basement reflection, too early to be a pegleg.

\section{Borehole Seismic Arrays}

Many of the errors discussed above can be eliminated by using a borehole array of receivers. The separation between sondes would be fixed by the cable length, so that depth errors are

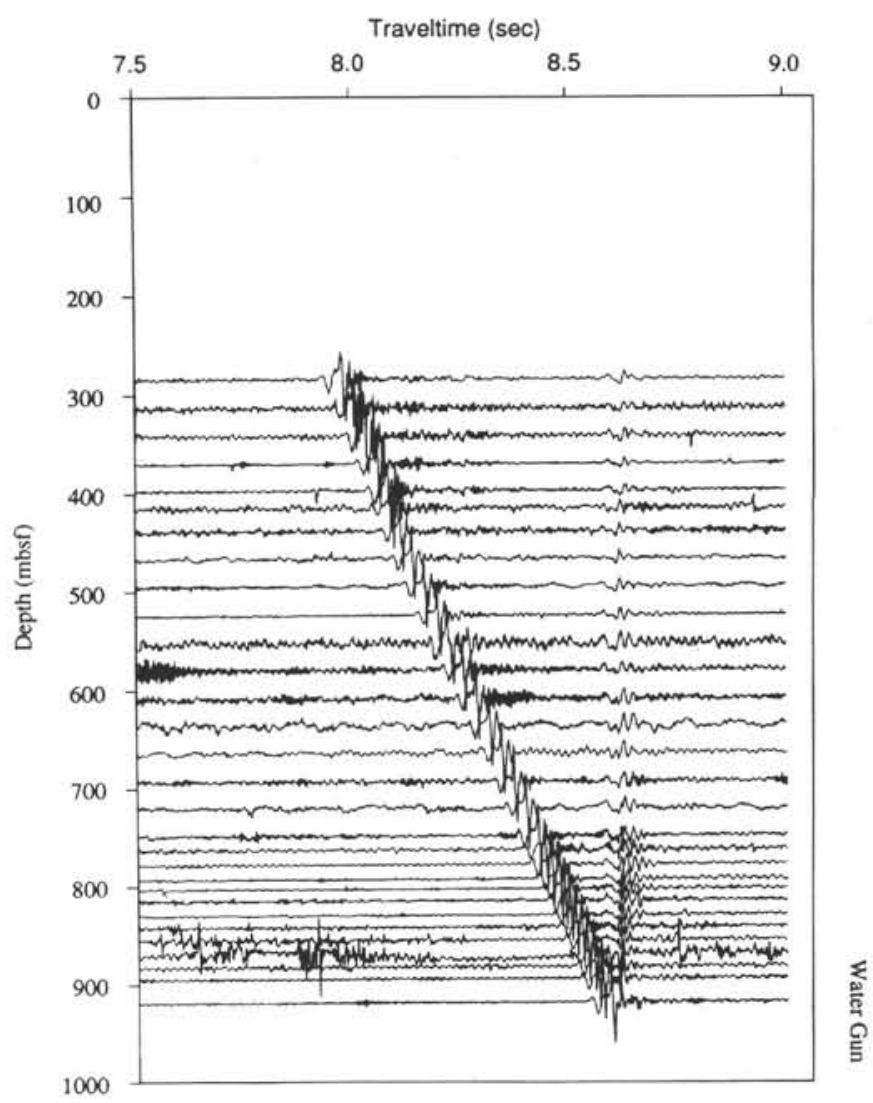

Figure 8 (continued).

eliminated. All sondes should receive the same shot, so that shot-instant errors should be eliminated. Selection errors might be minimized by cross-correlating signals from adjacent channels. However, the maximum frequency for reaching a given depth at measurable amplitude, and hence, the resolution of time selections will always be limited by sediment attenuation.

\section{CONCLUSIONS}

1. The first successful ODP VSP in a thick sedimentary section was acquired in the Argo Abyssal Plain at Site 765 during Leg 123.

2. Sources of noise in the data included electrical pick-up, material falling on the seismometer, heave-induced motion on the tool by the logging cable, and pipe noise. However, by summing individual traces at a given depth for each source, by performing velocity filtering on the data, and by deconvolving the upgoing energy with the downgoing waveform, good VSP records were obtained. The VSP records for air- and water-gun sources are in good agreement.

3. Good seismic data were acquired through the cased section of the hole in a section of sediments where sonic log results were spotty. Average velocities for the air-gun source were $1.967 \mathrm{~km} / \mathrm{s}$ ( $284 \mathrm{mbsf}$ to basement), $1.815 \mathrm{~km} / \mathrm{s}$ (186-284 mbsf) and 1.633 $\mathrm{km} / \mathrm{s}$ (seafloor to $186 \mathrm{mbsf}$, extrapolated). The average velocity for the water-gun source was $1.975 \mathrm{~km} / \mathrm{s}$. The difference in velocities for the two sources is consistent with dispersion estimates for sediments (Collins, 1988).

4. Separation of the wavefield into upgoing and downgoing components and deconvolution of the upgoing field clarified the seismic records and revealed the presence of reflectors that correlate with surface seismic profiles.

5. The deconvolved seismograms with their stacked traces, as well as a plot of air-gun two-way traveltime vs. depth, were used 


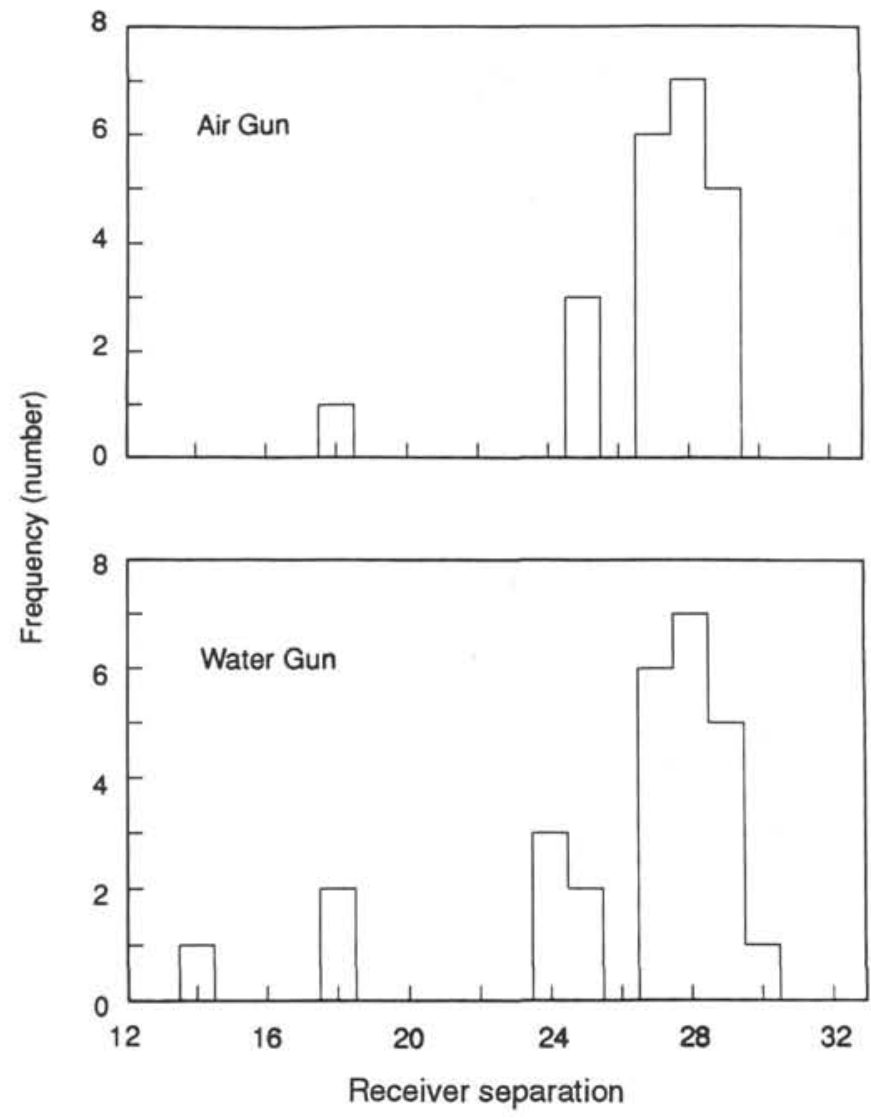

Figure 9. The distribution of receiver separations for the f-k filtering is shown. Most of the receivers are $28 \mathrm{~m}$ apart. To avoid aliasing, only frequencies below $30 \mathrm{~Hz}$ can be used, and resolution is limited.

to correlate the drilling results (lithologic units) with the seismic sequences at the drill site. These correlations can be used to extrapolate the drilling results regionally.

6. There is a weak sub-basement reflection at $8.86 \mathrm{~s}(600 \mathrm{~m}$ into basement), which may correspond to a contact between pillow basalts and sheet flows.

7. A correlation of VSP velocities with velocities obtained from laboratory measurements of cores and sonic logs shows discrepancies down to about 420 mbsf. Laboratory velocities are lower than VSP velocities, presumably due to disturbance of the core during drilling and recovery. Sonic log velocities are higher than VSP velocities presumably due to the effects of mud cake. Below about 420 mbsf, the data are in much closer agreement, straddling about $2.0 \mathrm{~km} / \mathrm{s}$.

8 . Interval velocity measurements over 12 - to 28 -m receiver separations were poor because of receiver depth and timing errors. We recommend that an array of borehole receivers be used for future interval velocity measurements. In addition, the shot-instant detection and recording system on board the JOIDES Resolution should be investigated for the source of scatter observed in our data.

\section{ACKNOWLEDGMENTS}

Preparation and deployment of the equipment involved several people.

We gratefully acknowledge the generous assistance of Roland Beaussillon, Robert R. Current, Ted Gustafson, Daniel Lizarralde, and Dwight E. Mossman. Patrick Thompson, Operations
Superintendent, carefully coordinated the deployment of our tool. John R. Eastlund facilitated the implementation of our processing software on the shipboard VAX. The SEDCO drilling crew handled the rigging and deployment of our equipment with care and dispatch.

Shipboard participation during Leg 123 was conducted with funds from the National Science Foundation, ODP, and U.S. Science Program administered by the Texas A\&M Research Foundation, Purchase Orders (\#20218 [WHOI] and \#20210 [UTIG]). The pre-cruise preparation of equipment was performed under P.O. No. 500 (WHOI) and the post-cruise analysís was conducted under P.O. Nos. 20304 (WHOI) and 20325 (UTIG). This is UTIG Contribution No. 832.

\section{REFERENCES}

Balch, A. H., and Lee, M. Y., 1984. Vertical Seismic Profiling: Techniques, Applications, and Case Histories: Boston (Int. Human Resour. Develop. Corp.).

Christie, P.A.F., Hughes, V. J., and Kennett, B.L.N., 1983. Velocity filtering of seismic reflection data. First Break, 1:9-24.

Collins, M. D., 1988. The time-domain solution of the wide-angle parabolic equation including the effects of sediment dispersion. J. Acoust. Soc. Am., 84:2114-2125.

Dey-Sarker, S. K., and Wiggins, R. A., 1976. Source deconvolution of teleseismic P-wave arrivals between $14^{\circ}$ and $40^{\circ}$. J. Geophys. Res., 81:3633-3641.

Dougherty, M. E., and Stephen, R. A., 1988. Seismic energy partitioning and scattering in laterally heterogeneous ocean crust. J. Pure Applied Geophys., 128:195-229.

Gal'perin, E. I., 1974. Vertical Seismic Profiling. Soc. Explor. Geophys. Hardage, B. A., 1983. Vertical Seismic Profiling, Part A: Principles: London (Geophysical Press).

Kommedal, J. H., and Tjøstheim, B. A., 1989. A study of different methods of wavefield separation for application to VSP data. Geophys. Prospect., 37:117-142.

LaTraille, S. L., 1983. Archiving and exchange of a computerized marine seismic database: the ROSE data archive system. Hawaii Inst. Geophys. Data Rept., 43:1-65.

Lee, M. W., and Balch, A. H., 1983. Computer processing of vertical seismic profile data. Geophysics, 48:272-287.

Mutter, J. C., and Balch, A., 1988. Vertical Seismic Profiling (VSP) and the Ocean Drilling Program (ODP): Report of a Workshop. Joint Oceanogr. Inst./U.S. Science Advisory Comm.).

Parkes, G., and Hatton, L., 1986. The Marine Seismic Source: Dordrecht (D. Reidel).

Rutledge, J. T., and Winkler, H., 1989. Attenuation measurements from vertical seismic profile data: Leg 104, Site 642. In Eldholm, O., Thiede, J., Taylor, E., et al., Proc. ODP, Sci. Results, 104: College Station, TX (Ocean Drilling Program), 965-972.

Shipboard Scientific Party, 1986. Site 418: Bermuda Rise. In Salisbury, M. H., Scott, J. H., Auroux, C. A., et al., Proc. ODP, Init. Repts., 102: College Station, TX (Ocean Drilling Program), 95-150.

1987. Site 642: Norwegian Sea. In Eldholm, O., Thiede, J., Taylor, E., et al., Proc. ODP, Init. Repts., 104: College Station, TX (Ocean Drilling Program), 53-454.

, 1988. Site 504: Costa Rica Rift. In Becker, K., Sakai, H., et al., Proc. ODP, Init. Repts., 111: College Station, TX (Ocean Drilling Program), 35-251.

1989. Site 735. In Robinson, P. T., Von Herzen, R., et al., Proc. ODP, Init. Repts., 118: College Station, TX (Ocean Drilling Program), 89-222.

1990. Site 765. In Ludden, J. N., Gradstein, F. M., et al., Proc. ODP, Init. Repts., 123: College Station, TX (Ocean Drilling Program), 63-267.

Stephen, R. A., 1979. The oblique seismic experiment in oceanic crust: experiment and technique. Mar. Geophys. Res., 4:213-226.

Swift, S. A., Hoskins, H., and Stephen, R. A., 1991. Seismic stratigraphy in a transverse ridge, Atlantis II Fracture Zone. In Von Herzen, R. P., 
Robinson, P. T., et al., Proc. ODP, Sci. Results, 118: College Station, TX (Ocean Drilling Program), 219-226.

Swift, S. A., Stephen, R. A., and Hoskins, H., 1988. Structure of upper oceanic crust from an oblique seismic experiment at Hole 418A, Western North Atlantic. In Salisbury, M. H., Scott, J. H., et al., Proc. ODP, Sci. Results, 102: College Station, TX (Ocean Drilling Program), 97-124.

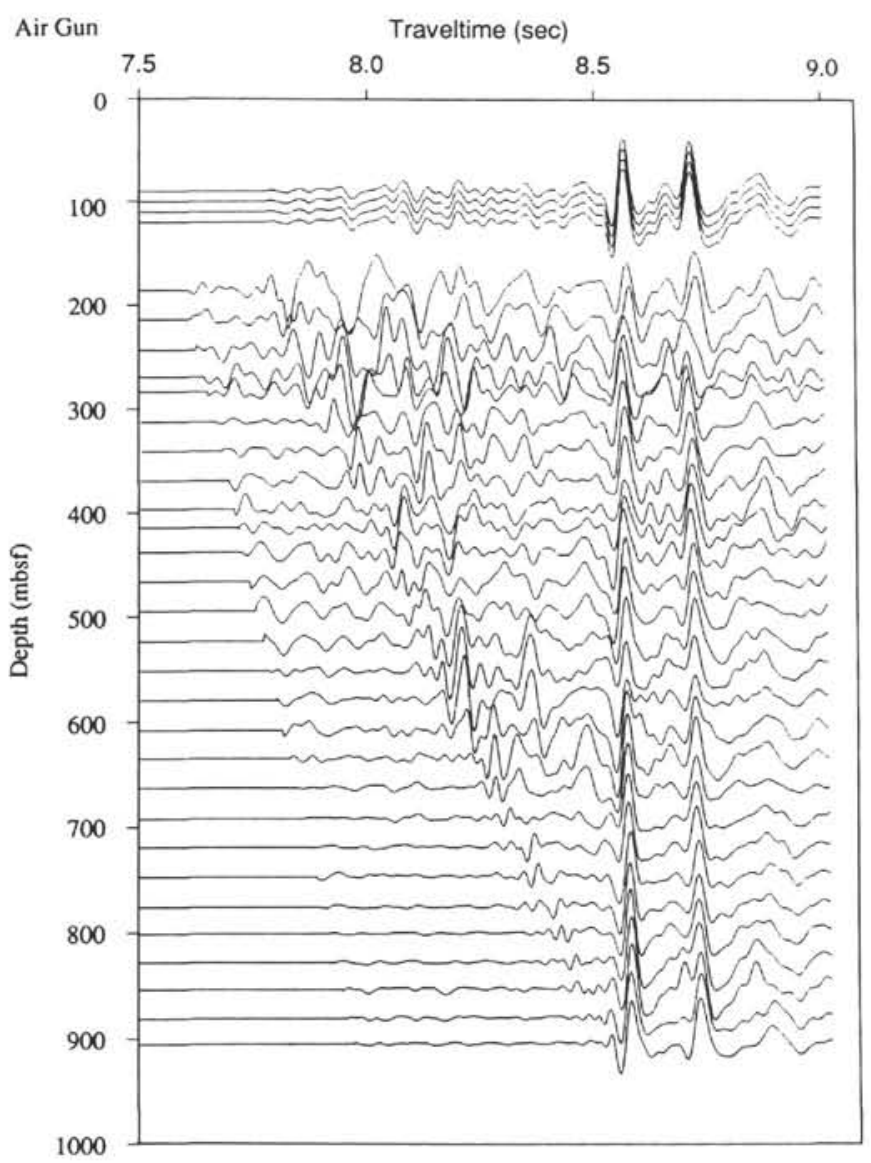

Figure 10. The upgoing wavefields after $\mathrm{f}-\mathrm{k}$ processing for air and water guns show sediment reflectors, particularly between 8.0 and $8.2 \mathrm{~s}$, that were not observed in the unfiltered data (Fig. 8). The traces between 90 and $150 \mathrm{mbsf}$ are a stack of the VSP data (traveltimes are for two-way propagation).
Weiderspahn, M., 1985. High resolution seismic acquisition and processing system (HIGHRES) - Ocean Drilling Program underway geophysics. Tech. Rep.-Inst. Geophys., Univ. Texas.

\section{Date of initial receipt: 5 June 1990}

Date of acceptance: 1 April 1991

Ms 123B-136

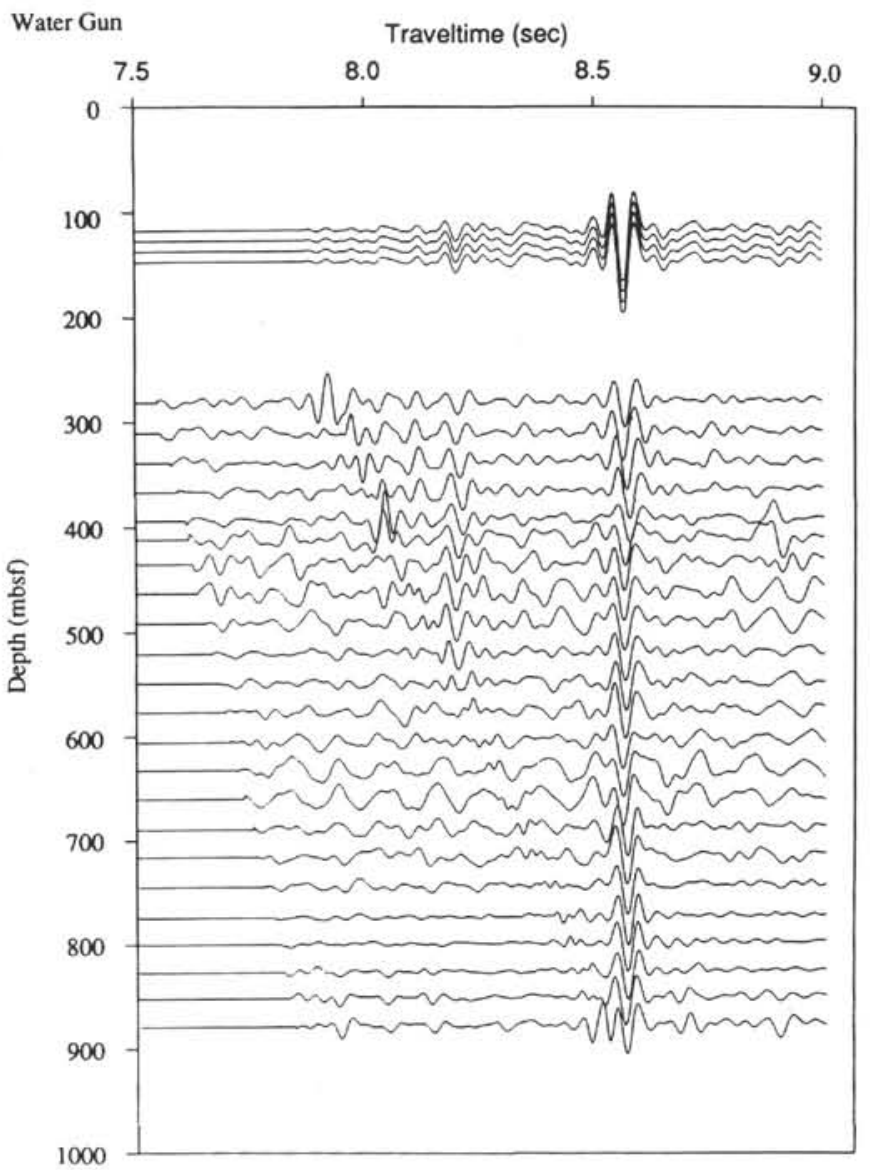

Figure 10 (continued). 


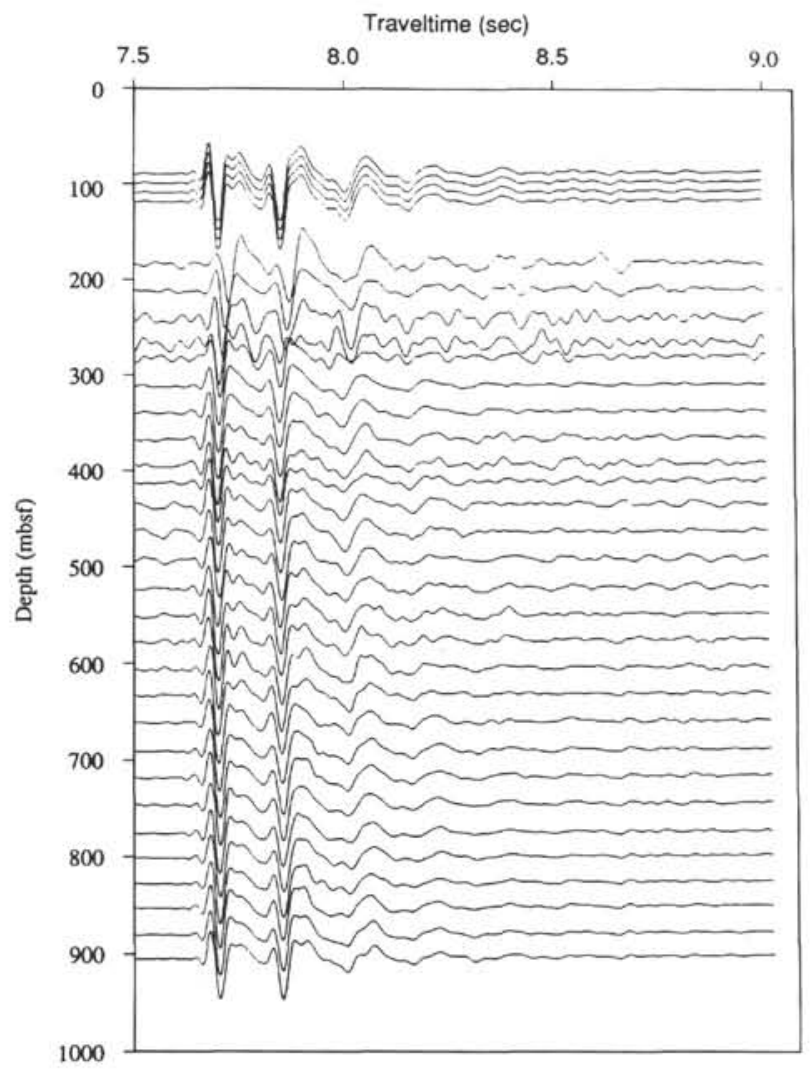

Figure 11. The downgoing wavefields after $\mathrm{f}-\mathrm{k}$ processing for air and water guns show that the incident energy is modified by Earth and are an excellent representation of the source field for deconvolution of the upgoing traces. The bubble pulse in the air-gun data is evident. The time scale is best-fit possible for two-way traveltime. The traces between 90 and $150 \mathrm{mbsf}$ are a stack of the VSP data (traveltimes are for two-way propagation).

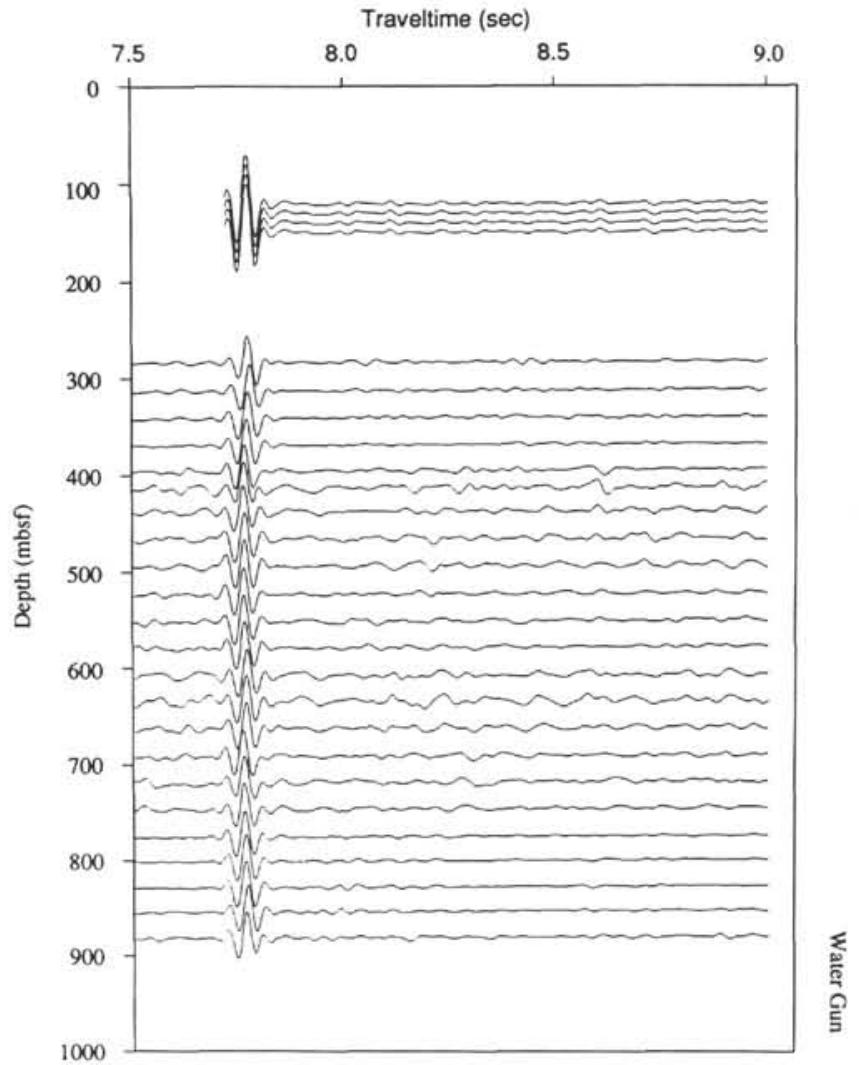

Figure 11 (continued). 
A

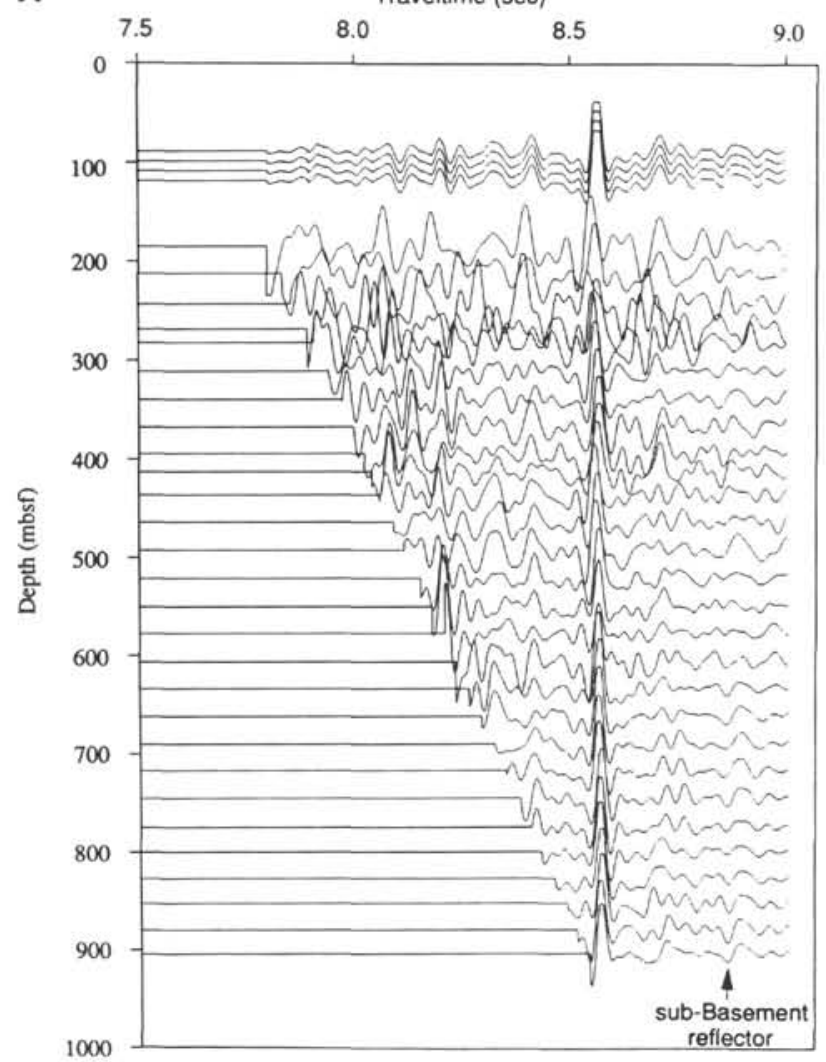

Figure 12. The deconvolved upgoing wavefields for the air (A) and water(B) guns are in good agreement. Processing revealed additional reflections in the sedimentary section between 8.25 and $8.55 \mathrm{~s}$ and a sub-basement reflector at $8.86 \mathrm{~s}$. The traces between 90 and $150 \mathrm{mbsf}$ are a stack of the deconvolved VSP data (traveltimes are for two-way propagation).

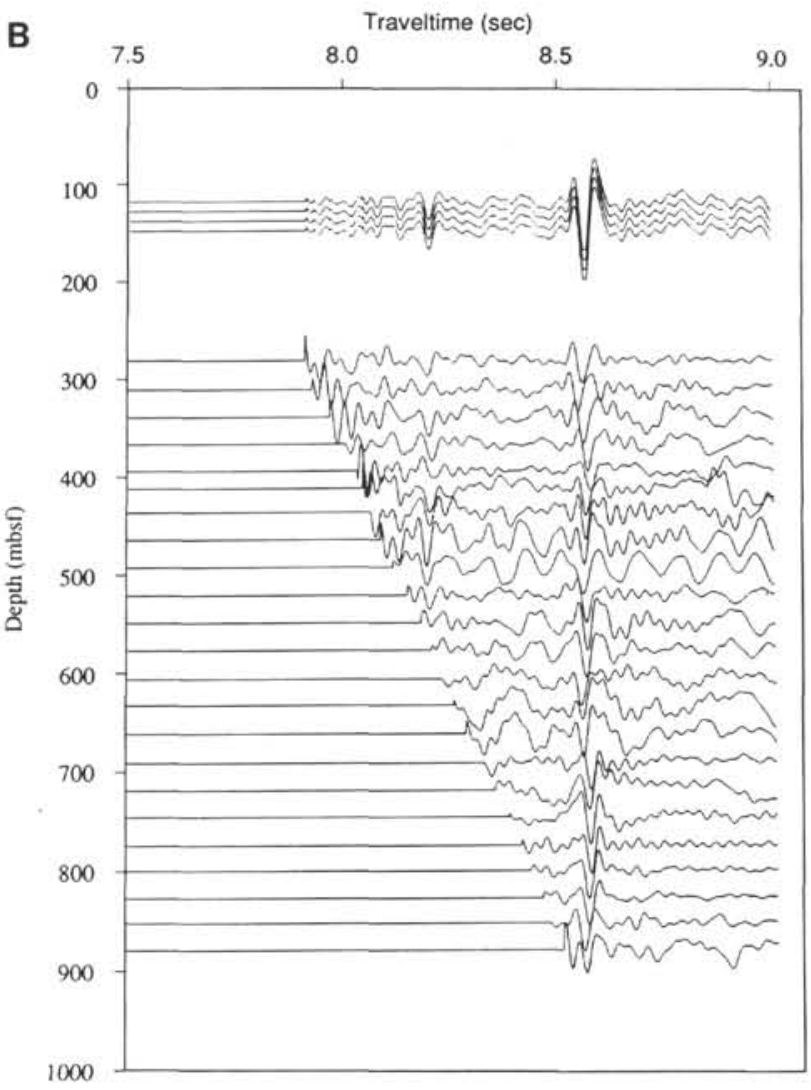




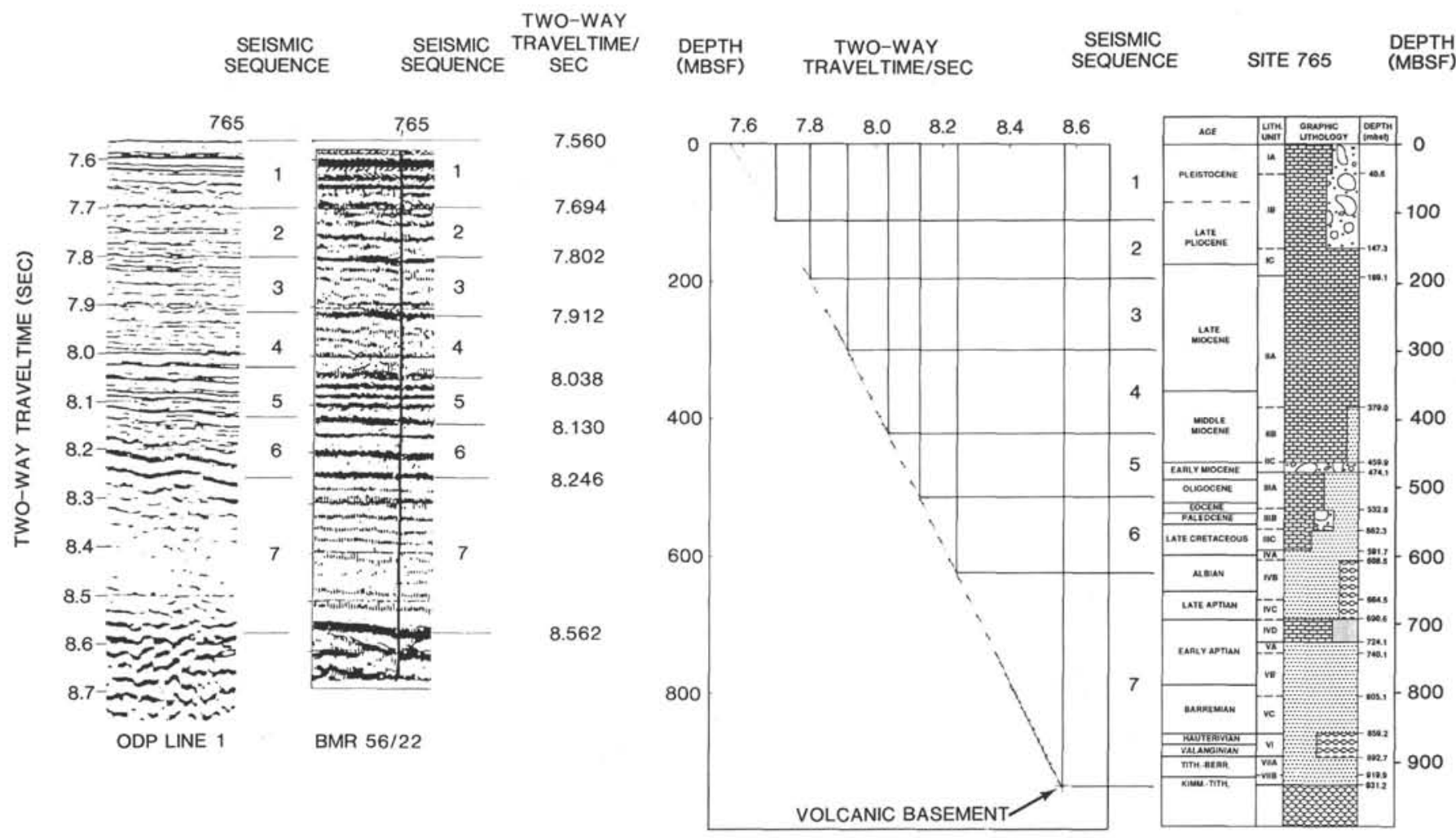

Figure 13. Plot of VSP air-gun traveltime (two-way) vs. depth from Figure 6A used to correlate seismic sequence boundaries with drilling results. Shown are portions of ODP singlefold seismic Line 1 shot with a water gun (left) and BMR multifold seismic Line 56/22 shot with an air gun (right) where they cross Site 765 (see text for discussion). 


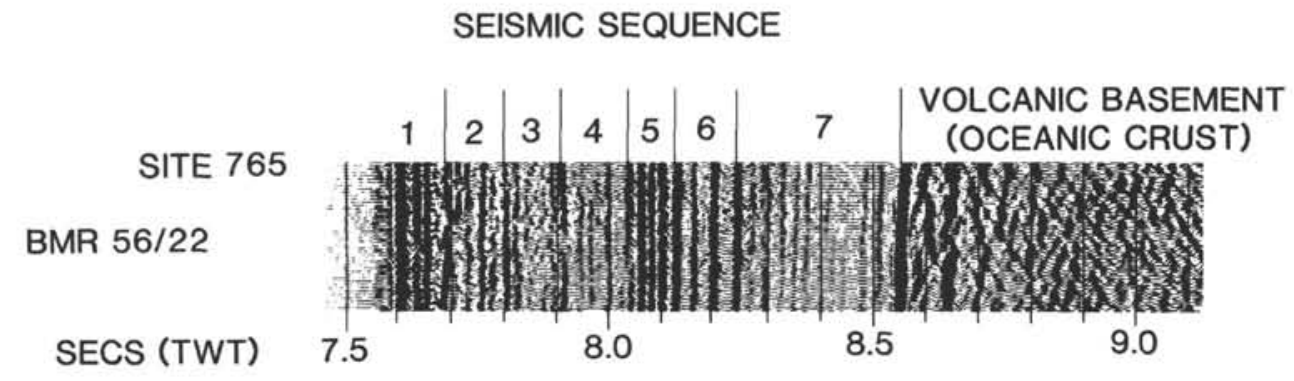

SEISMIC

SEQUENCE

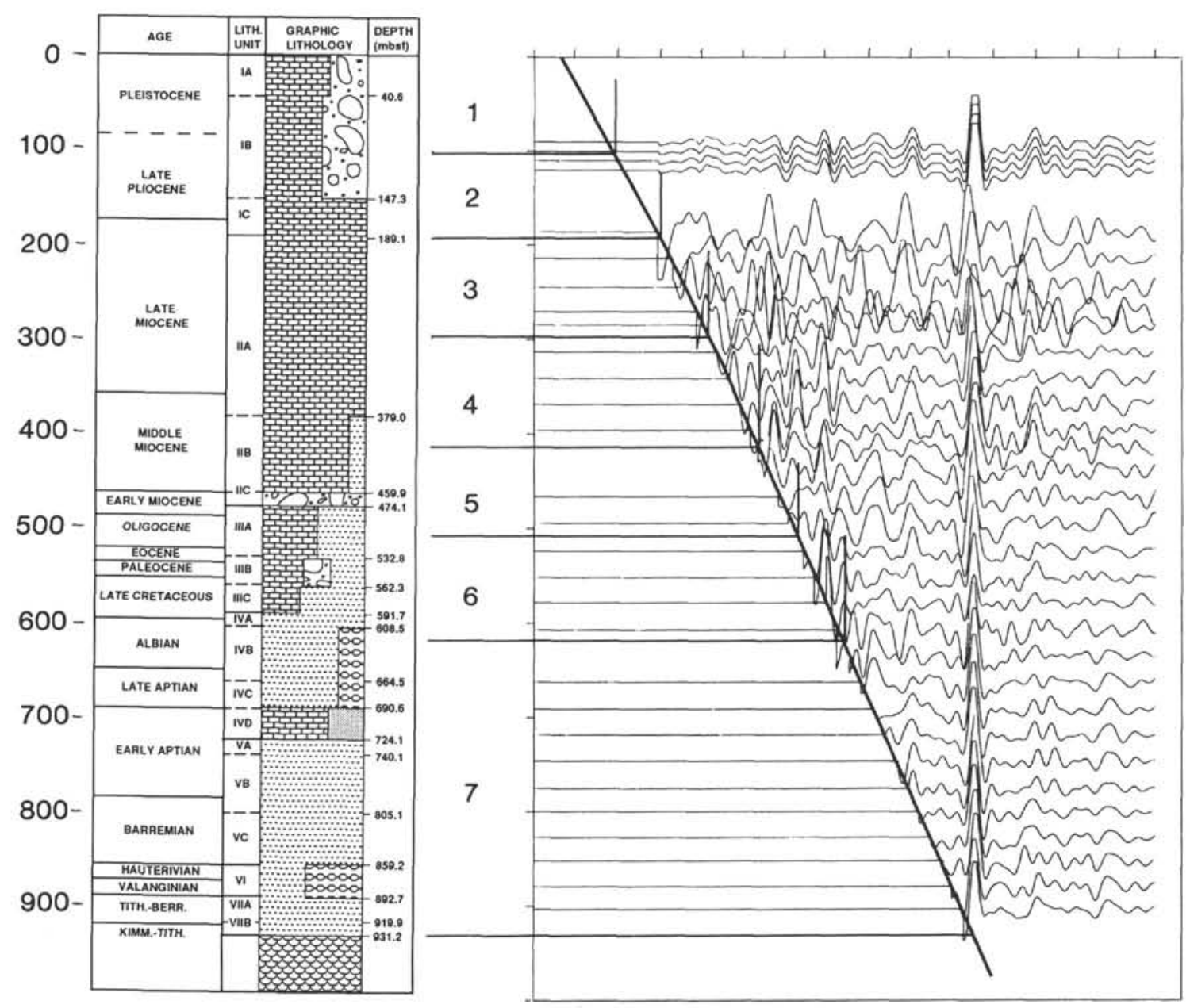

\section{DEPTH}

(mbsf)

Figure 14. The deconvolved air-gun seismogram with stacked traces above (from Fig. 12A) shows correlation with a portion of BMR seismic Line 56/22 (with seismic sequences) and drilling results at Site 765. 
SEISMIC SEQUENCE

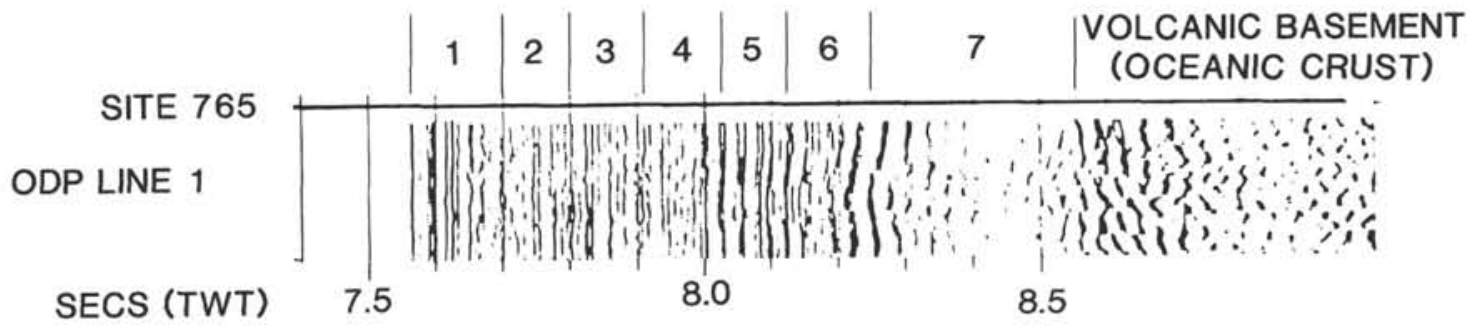

SEISMIC

SEQUENCE
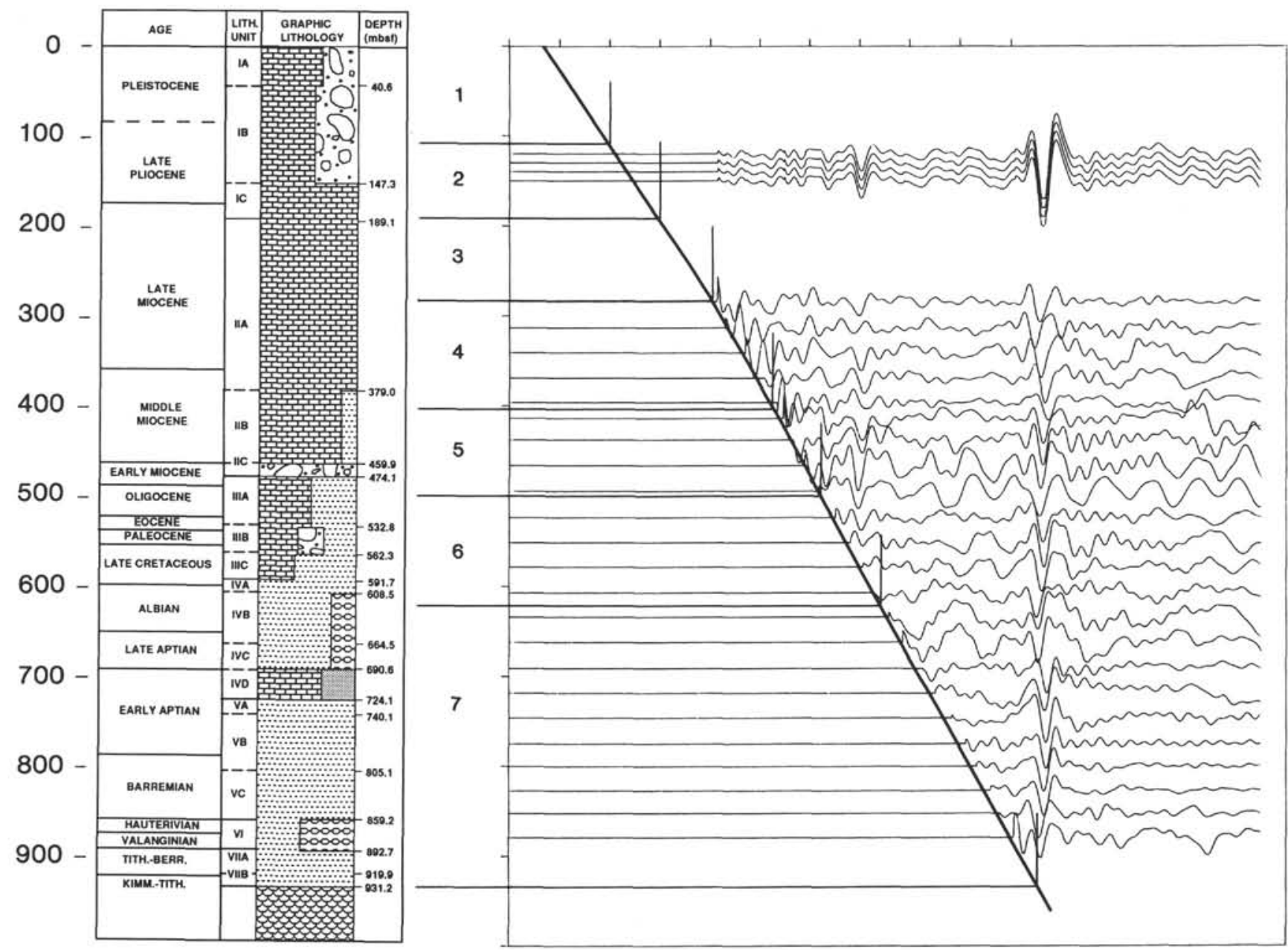

DEPTH

(mbsf)

Figure 15. The deconvolved water-gun seismogram with stacked traces above (from Fig. 12) shows correlation with a portion of ODP seismic Line 1 (with seismic sequences) and drilling results from Site 765. 


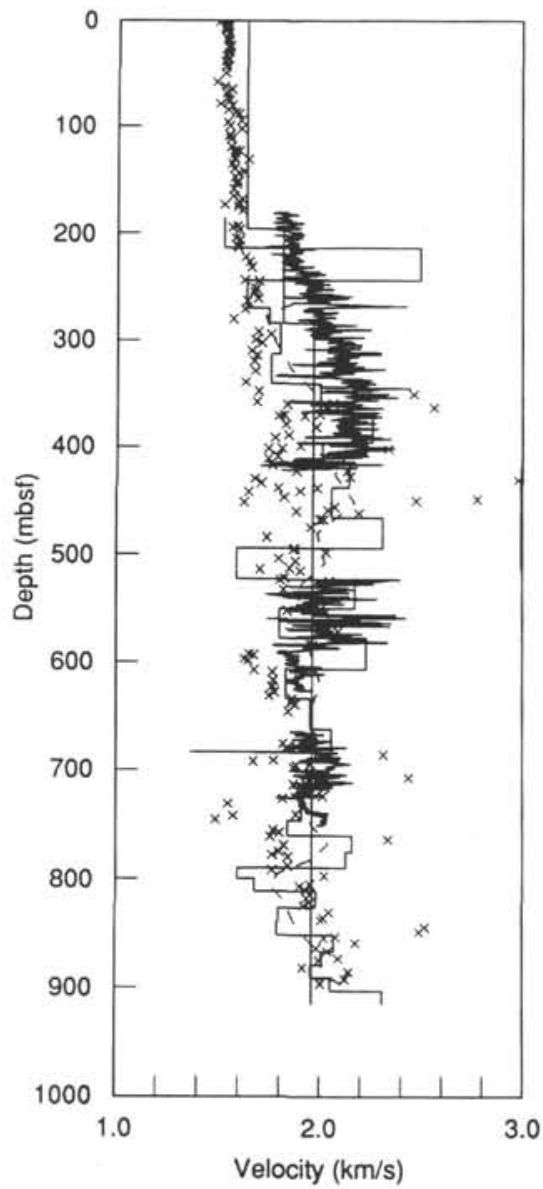

Figure 16. Laboratory, sonic-log, and VSP velocities are compared as a function of depth at the site. Laboratory velocities are generally the lowest, perhaps a result of disturbance of the core during drilling and recovery. Sonic and VSP velocities agree well below 420 mbsf. Above this, the VSP velocities are lower then the sonic velocities. Solid lines represent the unfiltered sonic-log data; crosses represent laboratory data; raw air-gun interval velocities are indicated by a blocky solid line; average air-gun interval velocities are indicated by dashed line; and three linear segment velocities from Figure 6 are indicated by vertical solid lines. 